\title{
Horizontally restrained rocking blocks: evaluation of the role of boundary conditions with static and dynamic approaches
}

\author{
Linda Giresini ${ }^{1}$, Mauro Sassu ${ }^{2}$ \\ Department of Energy, Systems, Territory and Constructions Engineering DESTEC \\ University of Pisa \\ ${ }^{1}$ linda.giresini@unipi.it,.2m.sassu@unipi.it
}

\begin{abstract}
The paper deals with the behavior of restrained rocking blocks under seismic actions. Structural or non-structural masonry or r.c. elements, such as building façades or pre-cast panels subjected to out-of-plane modes, may be assimilated to rocking blocks restrained by horizontal springs. Horizontal restraints can represent flexible floors or steel anchorages or any anti-seismic device designed to impede overturning probability. Their effect could improve, in most cases, the dynamic response of blocks in terms of reduction of rotation amplitude. Nevertheless, this effectiveness could vanish or, surprisingly, affect the response in negative way, resulting in overturning when low values of stiffness or one-sided motion in particular conditions are assumed. Two cases of horizontal restraints are analyzed: (i) concentrated restraint as single spring and (ii) smeared restraint as spring bed with constant or linearly variable stiffness. The single stabilizing or destabilizing terms of the formulation are here analyzed and commented, providing practical evaluations to obtain enhancement of response in static and dynamic perspective. A numerical example of a masonry façade with non-linear boundary conditions has been provided highlighting how the choice of stiffness values affects the oscillatory motion and rebound effects. Finally, unit stiffness for masonry/concrete walls and retrofitting techniques, such as steel tie-rods, has been calculated.
\end{abstract}

Keywords horizontal restraints; rocking; flexible roof; smeared restraint; masonry façade

\section{Introduction}

The identification of the behavior of rocking blocks is relevant to define their failure probability under seismic actions. Structural or non-structural elements of different buildings typologies can be assumed as rigid blocks. A typical example of r.c. rocking structures are pre-cast panels, frequently used in industrial or social buildings. These panels, particularly the non-structural ones, were demonstrated to be highly vulnerable to earthquakes if not properly connected to structural elements, as occurred in the 2012 Emilia Romagna Italian earthquake (Andreini et al. 2014, Giresini 2015). Moreover, walls of unreinforced masonry buildings are subjected to outof-plane modes that can be studied as rocking blocks. Obviously, the masonry texture has to be such to guarantee a monolithic behavior (Rovero et al. 2015). These issues can be faced by means of simplified methods based on static approaches, by performing kinematic linear/non linear analysis (NTC2008; 
Lagomarsino 2012) through classic limit analysis. Recent developments of these methods also including combinations of rocking, sliding and twisting in 3D rigid block formulations are contained in (Casapulla et al. 2014; Casapulla, Portioli 2016). The contribution of the present paper to these topics is reported in $\S 2.1$ and $\S 3.1$. In addition, out-of-plane modes may be analyzed with a more sophisticated procedure, evaluating the evolution of motion over time; the latter consists in the integration of equation of motion, generally considering the energy dissipation with a restitution coefficient that reduces rotation velocity after each impact. The contribution to these aspects is instead reported in $\S 2.2$ and 3.2.

The framework in which this work is developed is the Housner's formulation (Housner 1963), often used as basis of similar contributions related to rocking blocks (Makris, Vassiliou 2014; DeJong, Dimitrakopoulos 2014; Sorrentino et al. 2006). Free-standing blocks were shown to have high seismic stability and post-uplift resources when subjected to rocking motion. This aspect was recently discussed by Makris (2014) and related to the fact that rotational inertia increases with the square of the column size, whereas the overturning moment linearly increases with size. For such a good performance, the research field of rocking isolation is going to be more and more explored. The first experiments in this sense were done in New Zealand, where a reinforced concrete bridge pier with hysteretic dampers (Beck, Skinner 1973) and a chimney (Sharpe, Skinner 1983) were specifically designed to survive strong ground motion while rocking. However, the rocking behavior is strictly dependent on the ground motion type, as shown by DeJong (2012), who identified acceleration time histories causing 'rocking resonance' for various constraints. Moreover, the author found that a negative stiffness, due to rocking force-displacement law, prevents the resonance condition under constant frequency excitation. Indeed, the frequency content strongly affects the rocking motion: pulse-type records, typically characterized by high peak ground velocities and lower frequency content, result in large rocking amplitude (Makris, Roussos 2000), whereas non-pulse type records imply random responses (Acikgoz, DeJong 2014). Also artificial inputs can be defined to cause amplitude resonance over motion (Casapulla 2015).

Anyway, poor literature on rocking blocks subjected to particular boundary conditions is available (Makris, Vassiliou 2014; Giresini et al. 2015a). This configuration is more suitable to describe masonry and reinforced concrete panels that can be assimilated to rigid blocks. Indeed, those elements are generally horizontally connected to transverse walls, flexible roofs such as timber beams or vaults, tie-rods or a combination of them. Therefore, the need to investigate their response to recorded earthquakes emerges, together with the necessity to provide practical evaluation criteria to assess advantages or disadvantages caused by these restraints. Thus, in this paper, horizontal restraints are applied to rocking blocks to investigate their role in a dynamic perspective. A preliminary static approach is illustrated to provide an order of magnitude of the spring stiffness to apply to the block. In addition, information regarding its optimized position is given. Through the interpretation of the restoring moment term, the minimum value of stiffness for which the global system stiffness becomes from negative to positive can answer these questions. The dynamic contribution of horizontally restrained blocks is analyzed through the equation of motion and involves the rotational inertia, related to kinetic energy. Although an approach similar to the static one can provide some indications to the minimum stiffness to adopt, only a full rocking analysis is able to correctly predict the response.

Two cases of horizontal restraints are analyzed: (i) concentrated restraint as single spring with stiffness $K$ $=\left[\right.$ Force/Length] and (ii) smeared restraint as spring bed with stiffness of each spring $K^{\prime}=\left[\right.$ Force $/$ Length $\left.^{2}\right]$. First, the two cases are analyzed in static perspective by discussing the restoring moment expression and then equations of motion are obtained. For both static and dynamic approaches, indications about values of horizontal restraints are provided to get an enhancement of response. 


\section{Single horizontal restraint}

The model consists of a rectangular block rocking around an axis perpendicular to the $2 \mathrm{D}$ plane passing by $\mathrm{O}$ (Figure 1). The geometric characteristics of the block are the radius vector $R$, defining the position of the center of mass with respect to $\mathrm{O}$, and the slenderness ratio $\alpha$, arctangent of the ratio thickness $s$ to height $h$. The block, whose mass is $m$, might be connected to a flexible roof of mass $m_{r}$ (Figure 1a). The roof flexibility is modeled with a spring, assumed without eccentricity with respect to the block thickness. The roof mass $m_{r}$ changes the rotational inertia due to the variation of the centroid position, as explained in (Giresini et al. 2015b). Moreover, when the roof is inclined with specific boundary conditions, a horizontal destabilizing thrust may act as well (Giresini et al. 2015b). In the following the role of the roof mass $m_{r}$ is considered negligible with respect to the block mass $m$, considering only the dynamics of free or restrained elements without loads on the top. The block may be restrained by a single restraint (Figure 1a) or a smeared one (Figure 1b), both acting horizontally.

A concentrated horizontal restraint can represent, for civil engineering structures such as r.c. or masonry panels, steel tie-rods or timber bracings frequently installed before or after earthquakes to reduce further damages. Moreover, a single restraint could model horizontal floors connected to the block, such as vaults or arches whose equivalent stiffness can be determined by experimental or analytical tests (Giresini 2015c).

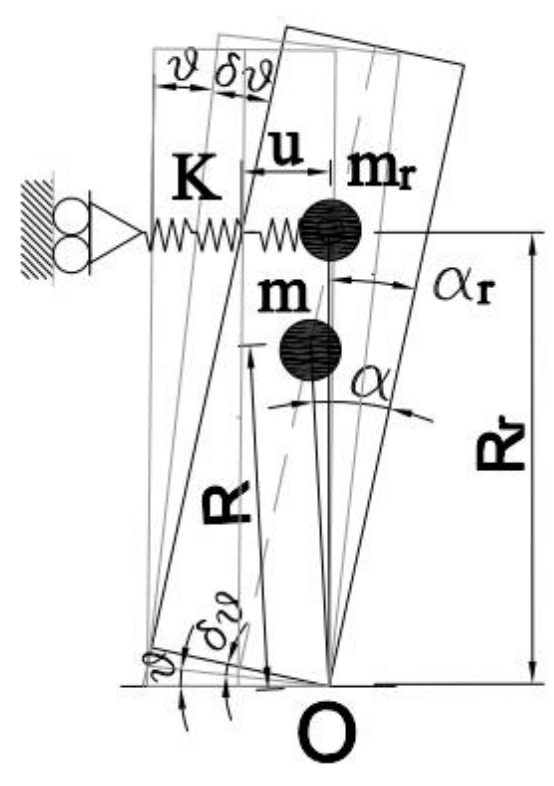

(a)

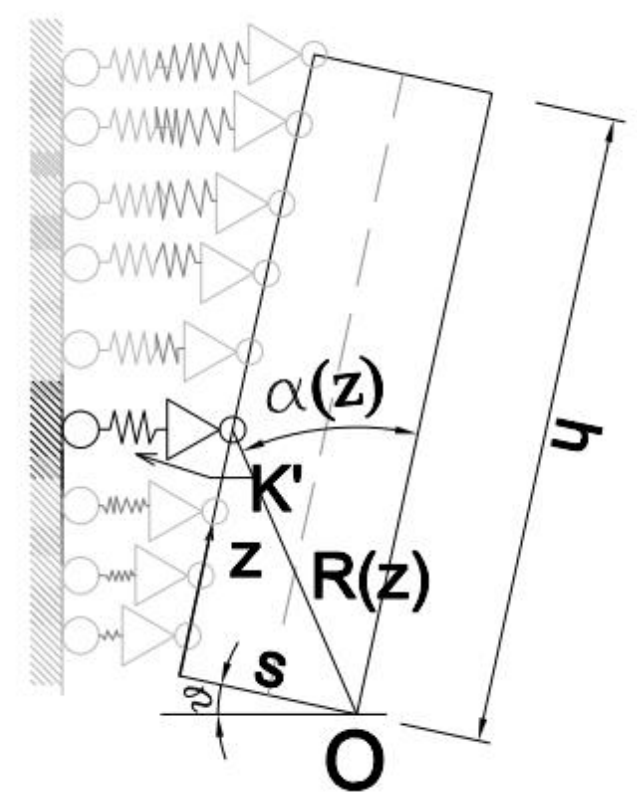

(b)

Figure 1. Single horizontal restraint with stiffness K (a) or horizontal spring bed K’ (b).

In this paper, only springs with linear behavior are considered for the first numerical case, to investigate the response by limiting uncertain parameters. Nevertheless, a non-linear constitutive law associated to the spring, due to different elasticity in tension and in compression, represents a more realistic assumption for civil engineering rocking structures. Indeed, often masonry or r.c. panels are connected to transverse walls, flexible roofs or strengthening techniques such as steel tie-rods acting in only one direction (Figure 9(a)). More in general, the stiffness could be sensitively different depending on the sign of rotation. For that reason, the solution of the following equations of motion should take it into account. The used MATLAB code for the 
case study presented in $\S 5$ contains an automatic events definition function that detects the rotation sign and attribute to K or K' pre-defined values. The constitutive law force-rotation is elastic (Figure 2) and a cut-off or a plastic phase with or without hardening could be included as well.

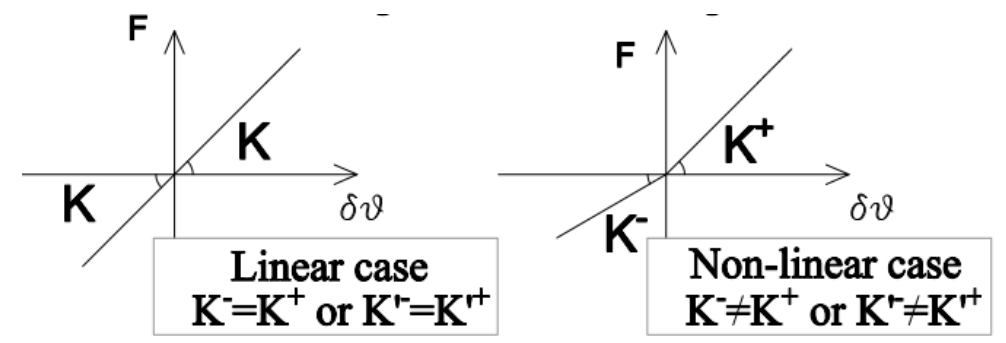

Figure 2. Definition of linear case and non-linear case for the elastic horizontal restraint

\subsection{Static approach}

The static approach is related to the definition of stabilizing and destabilizing effects in a perspective of limit analysis. A kinematic chain is assumed and the collapse multiplier can be calculated with equilibrium considerations. Let us assume the single-degree-of-freedom block restrained by a horizontal spring and let the initial deformed configuration be $\vartheta$. The virtual horizontal displacement $\delta u$, caused by an imposed virtual rotation $\delta \vartheta$ (Figure 1a), is expressed by:

$$
\delta u=R_{r} \cos \left[\alpha_{r}-\operatorname{sgn}(\vartheta) \vartheta\right] \delta \vartheta,
$$

where $R_{r}$ identifies the spring position, being the radius vector that connects the oscillation point $\mathrm{O}$ with the spring. Assuming that $\vartheta(t)>0$, without loss of generality, the finite horizontal displacement of the restrained point is then obtained by the definite integral over the interval $[0, \bar{\vartheta}]$ :

$$
u=R_{r}\left[\sin \alpha_{r}-\sin \left(\alpha_{r}-\bar{\vartheta}\right)\right]
$$

where $\bar{\vartheta}$ is the current rotation angle. When the block is rotated by an angle $\vartheta$, the horizontal restraint exerts a restoring moment $M_{r, K}(\vartheta)$ equal to:

$$
M_{r, K}(\vartheta)=\frac{\partial}{\partial \vartheta}(K u \delta u)=K R_{r}^{2} \cos \left(\alpha_{r}-\vartheta\right)\left[\sin \alpha_{r}-\sin \left(\alpha_{r}-\vartheta\right)\right] .
$$

Considering also the contribution of the self-weight and assuming that $R_{r}=\beta R$ with $0 \leq \beta \leq 2$, the global restoring moment $M_{r}(\vartheta)$ is:

$$
M_{r}(\vartheta)=m g R \sin (\alpha-\vartheta)+K \beta^{2} R^{2} \cos (\alpha-\vartheta)[\sin \alpha-\sin (\alpha-\vartheta)]
$$

For r.c. or masonry panels, generally $\beta \geq 1$. To avoid bouncing or sliding, slender blocks have to be considered. Let the Housner's limit of $\alpha<20^{\circ}=0.349 \mathrm{rad}$ (Housner 1963) be valid in the hypothesis of slender block. This means a height to thickness ratio $h / s>2.75$. Lipscombe \& Pellegrino (1993) studied the lower limit of $h / s$ for which bouncing stops within half oscillation cycle in a free vibration test. They found that for $h / s>2.75$ bouncing can be neglected if the restitution coefficient $e \leq 0.8$. For masonry and r.c. panels, commonly values of $h / s>5$ are taken into account, in such a way to exclude bouncing, usually being 
$e \leq 0.95$. Indeed, the theoretical value of $e_{H}=1-\frac{3}{2} \sin ^{2} \alpha$ (Housner 1963), for $\frac{h}{s}=5$ (that is $\alpha=0.197$ rad) gives $e_{H}=0.942$. The real restitution coefficient is generally lower than the theoretical one, due to geometrical imperfections or other damping effects, e.g. local plastic deformations (Casapulla et al. 2010).

Thus, for small rotations, $\sin \vartheta \cong \vartheta$ and $\cos \vartheta \cong 1$, Equation (4) becomes:

$$
M_{r}(\vartheta)=m g R \sin \alpha\left[1-\vartheta\left(\cot \alpha-\frac{K \beta^{2} R}{m g} \cot \alpha \cos \alpha\right)+\vartheta^{2} \frac{K \beta^{2} R}{m g} \cos \alpha\right]
$$

Linearizing to first order terms, the dimensionless restoring moment is:

$$
\frac{M_{r}(\vartheta)}{m g R}=\sin \alpha\left[1-\vartheta\left(\cot \alpha-\frac{K \beta^{2} R}{m g} \cot \alpha \cos \alpha\right)\right]
$$

The factor of the rotation angle $\vartheta$ in Equation (6) is the normalized system global stiffness, initially negative up to a limit value later defined. The global stiffness $K_{s y s}$ (Figure 3) is obtained from Equation (6):

$$
K_{\text {sys }}=m g R \cos \alpha\left(\frac{K \beta^{2} R}{m g} \cos \alpha-1\right)
$$

and Equation (6) becomes:

$$
M_{r}(\vartheta)=M_{r}(0)+K_{s y s} \vartheta
$$

where $M_{r}(0)=\operatorname{mgR} \sin \alpha$.

The condition for which the global stiffness $K_{\text {sys }}$ becomes positive is:

$$
\frac{K \beta^{2} R}{m g}>\frac{1}{\cos \alpha}
$$

If the block is rectangular, the weight $m g$ can be written in terms of the semi-diagonal $R$ and unit weight $\gamma$ as:

$$
m g=4 \gamma R^{2} \sin \alpha \cos \alpha d
$$

where $d$ is the depth of the block in the direction of the axis of rotation. By substituting Equation (10) in Equation (9) one has:

$$
\frac{K \beta^{2}}{R}>4 \gamma \sin \alpha d
$$

From this expression it is possible to formulate some considerations on the effectiveness of the single horizontal restraint. The resisting moment value for the configuration $\vartheta=0$ does not change, since the effect of $K$ intervenes for $\vartheta>0$ (Figure 3). Its static contribution depends upon the semi-diagonal $R$. For two blocks with same shape restrained by a spring with same $K$ and spring position (defined by the dimensionless parameter $\beta$ ), the larger block requires a higher value of $K$ or a higher position of the spring to obtain the same improvement in terms of global stiffness increase. 


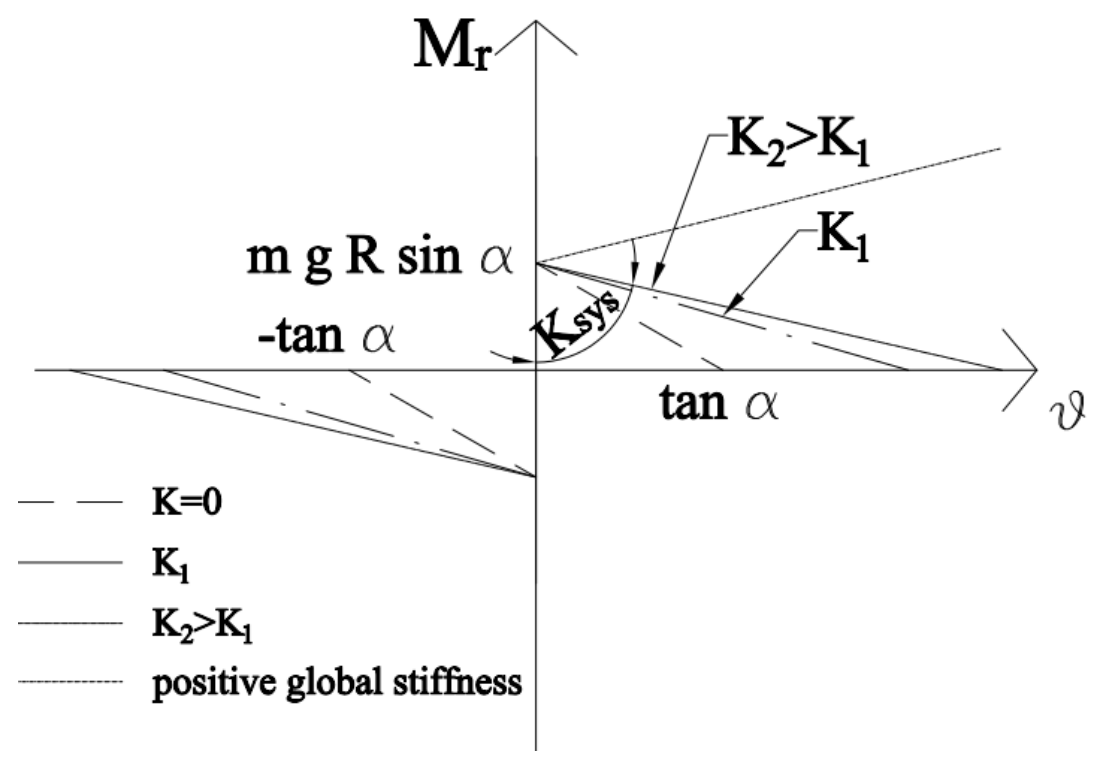

Figure 3. Resisting moment-rotation relationship and variation of global stiffness depending on the values of a single horizontal restraint.

By assuming, as numerical example, values of $R=1.5 \mathrm{~m}, \alpha=0.05 \mathrm{rad}$ (corresponding to height and thickness equal to $3.0 \mathrm{~m}$ and $0.15 \mathrm{~m}$ and (a) $\beta=1$ ) and an unit weight $\gamma=1.8 \mathrm{E} 4 \mathrm{~N} / \mathrm{m}^{3}$, one can evaluate the improvement obtained by adding a horizontal restraint with specific $K$ value (Figure 4(a)). When $K=1000$ $\mathrm{N} / \mathrm{m}$, a very low value for civil engineering restraints (for instance, it can be translated into a steel tie-rod of length $5.0 \mathrm{~m}$ and diameter $0.2 \mathrm{~mm}$ ), the rotation capacity increases by $20 \%$, passing from $\frac{\vartheta}{\alpha}=1.0$ to $\frac{\vartheta}{\alpha}=1.20$.

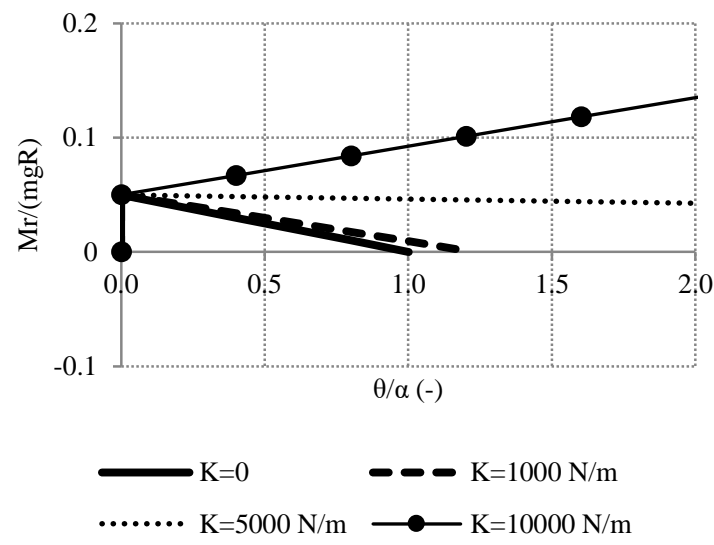

(a)

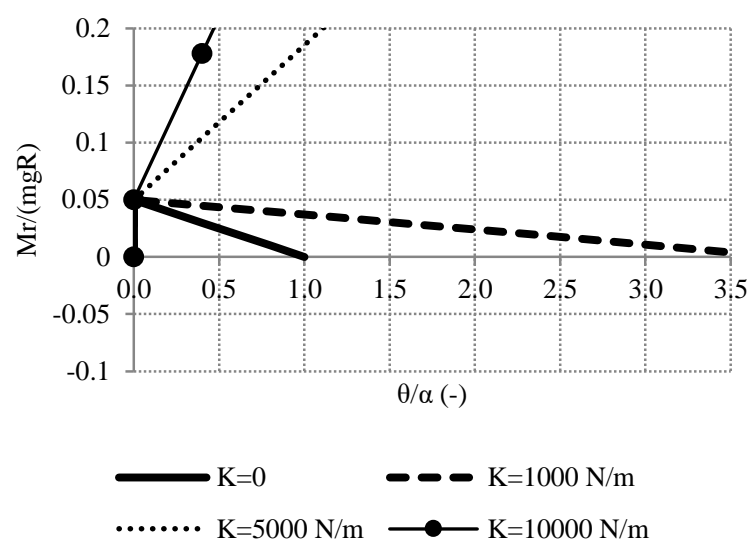

(b)

Figure 4 - Dimensionless moment-rotation amplitude diagram for different values of the dimensionless stiffness $\frac{K \beta^{2} R}{m g}$ of the horizontal restraint ( $\alpha=0.05 \mathrm{rad}$ and $R=1.5 \mathrm{~m}$ ) (a) $\beta=1$, (b) $\beta=2$ (Equation (4))

It is sufficient to assume a stiffness five times higher (corresponding to the same tie-rod with diameter $0.4 \mathrm{~mm}$ ) to get positive global stiffness. More precisely, the minimum $K$ value given by Equation (11) is equal to 5400 $\mathrm{N} / \mathrm{m}$. The effect is more positive if the position of the spring is higher, e.g. (a) $\beta=2$ namely at the corner top (Figure 4(b)). Thus, for common panels dimensions in civil engineering, there is a great enhancement of response even with low, but proper, values of horizontal restraint stiffness. It should be noticed that the difference between the non-linearized (Equation (4)) and the linearized (Equation (6)) expressions gives values of resisting moment different less than $1 \%$. Resisting moment values were calculated for different normalized 
rotation values from 0 to the maximum corresponding to a null resisting moment, with a range of 0.2 . The values so obtained have been then averaged obtaining the following error percentages. The difference increases (from an average value of $-0.53 \%$ for $\mathrm{K}=10000 \mathrm{~N} / \mathrm{m}$ to $-0.18 \%$ for $\mathrm{K}=1000 \mathrm{~N} / \mathrm{m}$ for $\beta=1$ ) when high stiffness values are considered. The resisting moment is therefore overestimated for high stiffness values, but this difference is negligible.

\subsection{Dynamic approach}

The contribution of the added spring in the equation of motion might not be conservative, namely could result in an unexpected overturning, even though the free-standing block is safe, depending on the type of action involved. For this reason, the necessity of comparing the destabilizing effect given by the earthquake with those stabilizing emerges.

The equation of motion can be written from the Housner's formulation including, in the Euler Lagrange equation, the potential energy equal to the work (Equation (3)) changed in sign:

$$
\begin{aligned}
& I_{0} \ddot{\vartheta}+\operatorname{sgn}(\vartheta) m g R \sin (\alpha-\operatorname{sgn}(\vartheta) \vartheta)+ \\
& +\operatorname{sgn}(\vartheta) K \beta^{2} R^{2} \cos \left(\alpha_{r}-\operatorname{sgn}(\vartheta) \vartheta\right)\left[\sin \alpha_{r}-\sin \left(\alpha_{r}-\operatorname{sgn}(\vartheta) \vartheta\right)\right]-m g \ddot{u}_{g} R \cos (\alpha-\operatorname{sgn}(\vartheta) \vartheta) \\
& \quad=0
\end{aligned}
$$

where $I_{0}$ is the polar inertia moment with respect to the oscillation point $\mathrm{O}, I_{0}=\frac{4}{3} \mathrm{~m}\left(\mathrm{~h}^{2}+\mathrm{s}^{2}\right)=\frac{4}{3} \mathrm{mR}^{2}$, and $\ddot{u}_{g}$ is the acceleration time-history (in gravity acceleration $g$ units). This equation can be re-written by distinguishing stabilizing and destabilizing terms:

$$
\ddot{\vartheta}+W_{S T A B}+K_{S T A B}+E_{D E S T}=0
$$

The stabilizing terms are:

$$
\begin{aligned}
W_{\text {STAB }} & =\operatorname{sgn}(\vartheta) \frac{m g R}{I_{0}} \sin (\alpha-\operatorname{sgn}(\vartheta) \vartheta)=\operatorname{sgn}(\vartheta) \frac{3}{4} \frac{g}{\mathrm{R}} \sin (\alpha-\operatorname{sgn}(\vartheta) \vartheta) ; \\
K_{S T A B}= & +\operatorname{sgn}(\vartheta) \frac{K \beta^{2} R^{2}}{I_{0}} \cos \left(\alpha_{r}-\operatorname{sgn}(\vartheta) \vartheta\right)\left[\sin \alpha_{r}-\sin \left(\alpha_{r}-\operatorname{sgn}(\vartheta) \vartheta\right)\right]= \\
= & \operatorname{sgn}(\vartheta) \frac{3 K \beta^{2}}{4 \mathrm{~m}} \cos (\alpha-\operatorname{sgn}(\vartheta) \vartheta)[\sin \alpha-\sin (\alpha-\operatorname{sgn}(\vartheta) \vartheta)]
\end{aligned}
$$

It must be noticed that the stabilizing term related to self-weight $W_{S T A B}$ has this positive effect for $|\vartheta|<\alpha$. When $|\vartheta|>\alpha$, this effect turns to negative. The term with destabilizing effect, representing the earthquake action, is:

$$
E_{D E S T}=-\frac{m g R}{I_{0}} \ddot{u}_{g} \cos (\alpha-\operatorname{sgn}(\vartheta) \vartheta)=-\frac{3}{4} \frac{g}{\mathrm{R}} \ddot{u}_{g} \cos (\alpha-\operatorname{sgn}(\vartheta) \vartheta)
$$

by assuming that the acceleration on the ground is the same as that experienced by the center of gravity of the block, due to its rigidity. In this paragraph, an approximate value of $K$ able to provide positive effect is determined. Naturally, it is not possible to state it exactly, since the evolution of motion depends on dissipation properties, generally identified in the restitution coefficient. Only a full integration of the equation of motion will give a completely reliable response assessment.

However, some indications on the minimum $K$ value to adopt can be furnished as follows. Let us consider again the block examined in the example of the previous paragraph $(\alpha=0.05 \mathrm{rad}, R=1.5 \mathrm{~m}, \beta=1-2, \gamma=1.8$ $\mathrm{E} 4 \mathrm{~N} / \mathrm{m}^{3}$ ). In a graph, where the stabilizing and destabilizing effects are reported (Figure 5), the earthquake 
can be initially assumed as constant acceleration value, like the PGA (peak ground acceleration) commonly considered in response spectrum seismic analysis. For $E_{D E S T}$, two different constant acceleration values $(0.50$ $\mathrm{g}$ and $0.20 \mathrm{~g}$ ) are assumed.

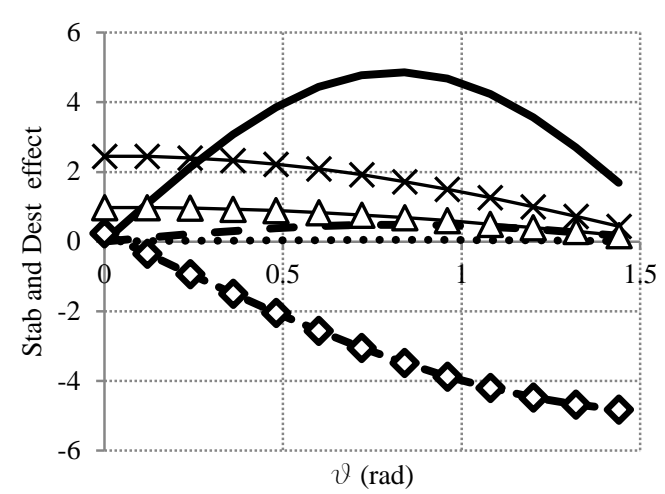

(a)

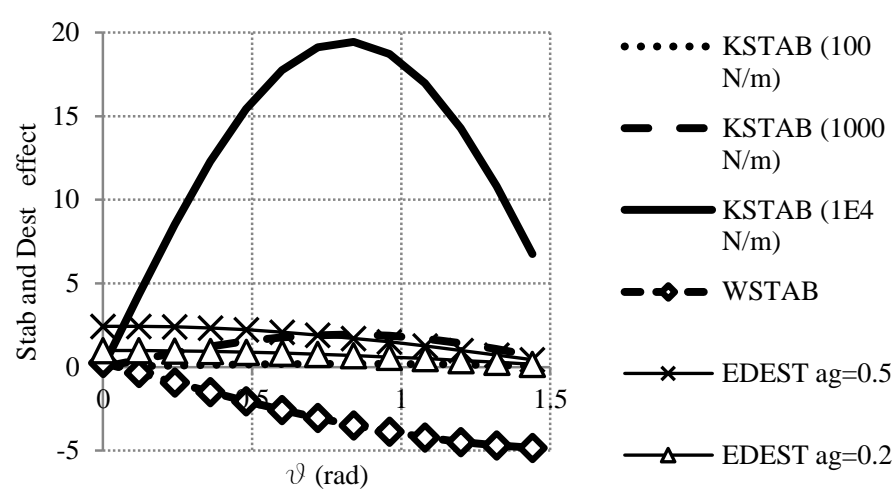

(b)

Figure 5. Stabilizing and destabilizing effects of the terms in the equation of motion, for (a) $\beta=1$ and (b) $\beta=2(\alpha=0.05 \mathrm{rad}, R=1.5 \mathrm{~m})$ - single horizontal restraint.

However, it is interesting to compare the effect of the stabilizing spring and the destabilizing earthquake action, even though it is simply a constant acceleration value. The cosine term is common to $K_{S T A B}$ and $E_{D E S T}$, while the maximum value of the sinus term in $K_{S T A B}$, named $f(\vartheta)$, can be obtained from its derivative:

$$
\frac{\partial f(\vartheta)}{\partial \vartheta}=\frac{\partial}{\partial \vartheta}\left[\sin \alpha_{r}-\sin \left(\alpha_{r}-\operatorname{sgn}(\vartheta) \vartheta\right)\right]=\cos \left(\alpha_{r}-\operatorname{sgn}(\vartheta) \vartheta\right) .
$$

The derivative equal to zero identifies the rotation $\overline{\bar{\vartheta}}$ for which $f(\overline{\bar{\vartheta}})$ is maximum:

$$
\overline{\bar{\vartheta}}=\alpha_{r}-\frac{\pi}{2} ; f(\overline{\bar{\vartheta}})=1+\sin \alpha_{r} .
$$

Anyway, the value $\overline{\bar{\vartheta}}=\alpha_{r}-\frac{\pi}{2}$ does not have physical sense, since the overturning condition is $\vartheta=\frac{\pi}{2}$. However, the maximum value of $f(\overline{\bar{\vartheta}})$ is equal to 2 . As general advice, to obtain effective results from a structural point of view, $K_{S T A B}$ should be at least three orders of magnitude with respect to $E_{D E S T}$, where their ratio is:

$$
\frac{K_{S T A B}}{E_{D E S T}}=\frac{K \beta^{2} R(1+\sin \alpha)}{m \ddot{u}_{g} \mathrm{~g}} \geq \frac{K \beta^{2} R}{\ddot{u}_{g} \mathrm{mg}}>1000
$$

if the block is slender so that $\alpha_{r} \cong \alpha$ and if $|\vartheta|<\alpha$. Being the stabilizing term related to self-weight $W_{\text {STAB }}$ negligible with respect to $K_{S T A B}$, is not considered in the numerator. Taking into account that strong ground motions reach a PGA ( $\left.\ddot{u}_{g} \mathrm{~g}\right)$ of the order of $1.0 \mathrm{~g}$, assuming that the spring is applied, at least, at the middle of the block $(\beta=1)$ or higher $(1<\beta \leq 2)$, it can be deduced that the minimum $\mathrm{K}$ required, estimated by the simple above procedure, should be:

$$
K_{\min }=1000 \frac{\mathrm{mg}}{R}
$$

That means, in the proposed numerical example, a minimum stiffness value around $5.4 \mathrm{E} 6 \mathrm{~N} / \mathrm{m}$. When $|\vartheta|>$ $\alpha$, the self-weight effect turns to negative. Therefore, this "efficiency ratio" becomes: 


$$
\frac{K_{S T A B}}{E_{D E S T}+W_{D E S T}}=\frac{\frac{K \beta^{2} R(1+\sin \alpha)}{m g}}{\ddot{u}_{g}+\tan (|\vartheta|-\alpha)}
$$

The term $\tan (|\vartheta|-\alpha)$ assumes a maximum value governed by typical physical r.c. or masonry panels, whose maximum slenderness can attain a value of 50 (e.g., thickness of $0.1 \mathrm{~m}$ and height of $5.0 \mathrm{~m}$ or $\tan (\alpha)=0.02$ ). Thus, $\tan (|\vartheta|-\alpha)_{\max }=\tan \left(\frac{\pi}{2}-0.02\right) \cong 50$ and the limit ratio can be expressed as:

$$
\frac{K_{S T A B}}{E_{D E S T}+W_{D E S T}}=\frac{\frac{K \beta^{2} R(1+\sin \alpha)}{m g}}{\ddot{u}_{g}+50}>1000
$$

which means:

$$
K_{\min }=50000 \frac{\mathrm{mg}}{R}
$$

assumed that the stabilizing term has to be at least three orders of magnitude higher than the destabilizing term. Naturally, the value expressed in Equation (22) is an upper limit of the minimum. The minimum stiffness can be computed for the case under examination with Equation (21) by substituting the current values of $\alpha$ and $\ddot{u}_{g}$. In the numerical example, the minimum stiffness is $K_{\min }=2.7 \mathrm{E} 8 \mathrm{~N} / \mathrm{m}$.

To numerically verify these assessments, a rocking analysis is performed in MATLAB to solve the equation of motion for the same block. The acceleration time-history assumed is the well known El Centro earthquake ground motion (Imperial Valley 5/19/40 04:39, El Centro array 9, 180) with PGA=0.348 g and PGV=33.5 $\mathrm{cm} / \mathrm{s}$. An incremental analysis is performed by changing the factor multiplying the acceleration values Ampl. to focus on the range where the collapse of the block is more likely to occur. By taking into account the fore mentioned considerations, values of stiffness from 0 to $\mathrm{K}=1 \mathrm{E} 6 \mathrm{~N} / \mathrm{m}$ are assumed. The incremental analysis is stopped at an amplification factor equal to 1.2 , corresponding to a PGA $=0.418 \mathrm{~g}$. This way, one is inside the range of $0.2<\ddot{u}_{g}<0.5$ of Figure 5. However, by substituting the values of $\alpha$ and $\ddot{u}_{g}$ (equal to $0.348 \mathrm{~g}$ ), Equation (18) gives $K_{\min }=1.9 \mathrm{E} 6 \mathrm{~N} / \mathrm{m}$. If one assumes to have $|\vartheta|>\alpha$, the minimum stiffness should be equal to $1.5 \mathrm{E} 6 \mathrm{~N} / \mathrm{m}$ (Equation (21)). Therefore, Equation (22) clearly overestimates the minimum value. The difference of minimum stiffness given by Equation (18) and Equation (22) is negligible, and one can assume then about $2.0 \mathrm{E} 6 \mathrm{~N} / \mathrm{m}$. All the rocking analyses are performed by adopting the same stiffness value in clockwise and counterclockwise rotation. The restitution coefficient is that theoretical, provided by Housner (1963), in favor of safety.

Results are displayed in Table 1 in terms of maximum ratios of normalized rotation amplitude $(\vartheta / \alpha)_{\max }$. The free-standing block overturns for an amplification factor of 1.20. It must be noticed that in a dynamic rocking analysis, despite of a kinematic approach, the block could survive for $\frac{\vartheta}{\alpha}>1$. Low stiffness values, $\mathrm{K}=100$ $1000 \mathrm{~N} / \mathrm{m}$, do not positively affect the response: indeed, the block is unstable when the restraint is both at the top corner and at the middle of the block. This suggests that low stiffness values not only do not influence the response, but could cause block overturning amplifying rocking motion. The block can collapse with a restoring force even though, when it is free-standing, does not collapse. This occurs because of the change of vibration period (variable with amplitude), which could be closer to that of the excitation resulting in resonance condition. For this reason, it becomes important to evaluate an order of magnitude of minimum stiffness value to reduce the rotation amplitude to acceptable values. Values of $K=100 \mathrm{~N} / \mathrm{m}$ and $\mathrm{K}=1000 \mathrm{~N} / \mathrm{m}$ are indeed of the same order of magnitude as the destabilizing term, as displayed in Figure 5. A spring with $\mathrm{K}=1 \mathrm{E} 4-1 \mathrm{E} 5$ 
$\mathrm{N} / \mathrm{m}$ allows stable rocking; nevertheless, the rotation amplitude $(\vartheta / \alpha)_{\max }$ attains maximum values higher than those of the case without restraint (except the case $K=1 E 5 \mathrm{~N} / \mathrm{m}$ and $\beta=2$ ). In these cases, the position of the spring at the top of the block $(\beta=2)$ gives maximum rotations from $30 \%$ to $50 \%$ lower than the spring located at the middle of the block $(\beta=1)$.

Higher values, such as $1 \mathrm{E} 6 \mathrm{~N} / \mathrm{m}$ in this example (corresponding to a steel tie-rod of diameter $6.0 \mathrm{~mm}$ and length $5.0 \mathrm{~m}$, acting in both directions), are recommended to attain safe values of maximum rotation amplitude $(\vartheta / \alpha)_{\max }$, since these values are lower than those without any restraint. For this order of magnitude the global system stiffness is largely positive (Figure 4). Thus, the minimum stiffness values given by Equations (18)(21) are reliable, as they guarantee safe rocking motion. For K>1E6 N/m, the amplitude ratio tends to zero (results not reported), confirming the benefit of the restraint.

Table 1 - Maximum ratios of normalized rotation amplitude obtained from incremental rocking analysis $(\alpha=0.05 \mathrm{rad}, R=1.5 \mathrm{~m}$, El Centro earthquake, Ampl.= amplification factor $)$

\begin{tabular}{|c|c|c|c|c|c|c|}
\hline Ampl. & $K=0 \mathrm{~N} / \mathrm{m}$ & $K=100 \mathrm{~N} / \mathrm{m}$ & $K=1000 \mathrm{~N} / \mathrm{m}$ & $K=1 E 4 \mathrm{~N} / \mathrm{m}$ & $K=1 E 5 \mathrm{~N} / \mathrm{m}$ & $K=1 E 6 \mathrm{~N} / \mathrm{m}$ \\
\hline 1.0 & 0.712 & overturning & overturning & 2.935 & 0.906 & 0.2216 \\
\hline 1.1 & 0.839 & overturning & overturning & 3.196 & 1.212 & 0.2412 \\
\hline 1.2 & overturning & overturning & overturning & 3.371 & 1.570 & 0.2584 \\
\hline \multicolumn{7}{|l|}{$\beta=2$} \\
\hline Ampl. & $K=0 \mathrm{~N} / \mathrm{m}$ & $K=100 \mathrm{~N} / \mathrm{m}$ & $K=1000 \mathrm{~N} / \mathrm{m}$ & $K=1 E 4 \mathrm{~N} / \mathrm{m}$ & $K=1 E 5 \mathrm{~N} / \mathrm{m}$ & $K=1 E 6 \mathrm{~N} / \mathrm{m}$ \\
\hline 1.0 & 0.712 & overturning & 3.128 & 2.069 & 0.402 & 0.039 \\
\hline 1.1 & 0.839 & overturning & overturning & 2.264 & 0.451 & 0.044 \\
\hline 1.2 & overturning & overturning & overturning & 2.431 & 0.486 & 0.049 \\
\hline
\end{tabular}

In conclusion, it is possible to numerically estimate the weight of the restoring moment, given by self-weight and horizontal restraint, with respect to the applied ground motion. The check of these terms can provide a first insight on the effectiveness of the strengthening system, by means of the simple formula of Equations (18)-(22), before performing rocking analysis. It must be noticed that strengthening measures generally act only in one-sided motion. In this case, numerical unstable effects can emerge when a finite value of stiffness is assumed for a clockwise rotation and zero value is considered for a counterclockwise rotation (Giresini et al. 2015a). For a numerical application of such a non-linear conditions, see $\S 5$.

\section{Smeared horizontal restraints}

The second considered configuration consists of a rectangular block restrained by smeared horizontal elastic restraints (Figure 1(b)). The height and thickness are respectively labeled $h$ and $s$. Each spring of the elastic "bed" is located at a distance $R(z)$ with respect to the oscillation point O. Let the angle formed by the panel side and $R(z)$ be $\alpha(z)$. The dimensions of each spring of stiffness $K^{\prime}$ is [Force/Length ${ }^{2}$ ]. Smeared horizontal restraints can model transverse connecting walls or added layers with assigned stiffness, due to a vertical distribution of tie-rods or similar anchorages.

\subsection{Static approach}

Analogously to the procedure illustrated in $\S 2$, the stabilizing effect of the horizontal restraints is here investigated. The generic spring $K^{\prime}$, uniformly distributed along the vertical side, is considered at depth $z$; the 
axis $z$ rotates with the rotation of the block. The corresponding radius vector $R(z)$ is function of $z$ and the angle formed with the wall is $\alpha(z)$. The horizontal virtual displacement $\delta u$ at a generic $\mathrm{z}$ is in the deformed configuration of Figure 1(b) is:

$$
\delta u(z)=R(z) \cos [\alpha(z)-\operatorname{sgn}(\vartheta) \vartheta] \delta \vartheta,
$$

The finite displacement is then obtained by integrating Equation (23) over the interval $[0, \bar{\vartheta}]$, where $\bar{\vartheta}$ is the fixed current rotation:

$$
u(z)=R(z)\{\sin \alpha(z)-\sin [\alpha(z)-\operatorname{sgn}(\vartheta) \bar{\vartheta}]\},
$$

The virtual work done by the spring with constant stiffness $K^{\prime}$ is calculated by imposing a virtual differential displacement with respect to the virtual rotation angle $\delta \vartheta$.

When the block is rotated by an angle $\vartheta$, the generic horizontal restraint with stiffness $K^{\prime}$ exerts a restoring moment $M_{r, K^{\prime}}(\vartheta)$ equal to:

$$
M_{r, K^{\prime}}(\vartheta)=\frac{\partial \delta W(z)}{\partial \vartheta}=\frac{\partial}{\partial \vartheta}\left[K^{\prime} d z \cos \vartheta u(z) \delta u(z)\right]
$$

being $d z \cos \vartheta$ the influence length of the single spring at depth $z$ and $W(z)$ the corresponding work done. Substituting in Equation (25) Equations (23)-(24), the work $W(z)$ becomes:

$$
\delta W_{\mathrm{z}}=-\operatorname{sgn}(\vartheta) K^{\prime} R(z)^{2} \cos [\alpha(z)-\operatorname{sgn}(\vartheta) \vartheta]\{\sin \alpha(z)-\sin [\alpha(z)-\operatorname{sgn}(\vartheta) \bar{\vartheta}]\} \cos \vartheta \sin \delta \vartheta d z,
$$

The work $\delta W$ along the vertical side of the block is then calculated by integrating Equation (26) over the interval $[0, h]$ in $d z$ with $R(z)=\sqrt{s^{2}+z^{2}}$ :

$$
\begin{aligned}
\delta W=\int_{0}^{h} \delta W_{\mathrm{z}}= & -\operatorname{sgn}(\vartheta) K^{\prime} \cos \vartheta \sin \delta \vartheta \int_{0}^{h}\left(\mathrm{~s}^{2}\right. \\
& \left.+\mathrm{z}^{2}\right)[\cos \alpha(z) \cos \vartheta+\operatorname{sgn}(\vartheta) \sin \alpha(z) \sin \vartheta][\sin \alpha(z)(1 \\
& -\cos \vartheta)+\operatorname{sgn}(\vartheta) \cos \alpha(z) \sin \vartheta] \mathrm{dz} .
\end{aligned}
$$

It is convenient to express the trigonometric functions in terms of coordinate $z$ and thickness $s$ :

$$
\cos \alpha(z)=\frac{z}{\sqrt{s^{2}+z^{2}}} ; \sin \alpha(z)=\frac{s}{\sqrt{s^{2}+z^{2}}}
$$

This way, the expression of work done by the spring bed is simplified in:

$$
\begin{aligned}
\delta W=-\operatorname{sgn}(\vartheta) & K^{\prime} \cos \vartheta \sin \delta \vartheta \int_{0}^{h}(\mathrm{z} \cos \vartheta \\
& +\operatorname{sgn}(\vartheta) \sin \vartheta)[\mathrm{s}(1-\cos \vartheta)+\operatorname{sgn}(\vartheta) \mathrm{z} \sin \vartheta] \mathrm{dz} .
\end{aligned}
$$

Equation (29) can be expressed in the short form:

$$
\delta W=-\operatorname{sgn}(\vartheta) K^{\prime} \sin \delta \vartheta \int_{0}^{h} \mathrm{~A}+\mathrm{B} \mathrm{z}+\mathrm{C} \mathrm{z}^{2} \mathrm{dz},
$$

where: 


$$
\begin{aligned}
& A=\operatorname{sgn}(\vartheta) s^{2} \sin \vartheta \cos \vartheta(1-\cos \vartheta) \\
& B=s\left(\sin ^{2} \vartheta \cos \vartheta-\cos ^{3} \vartheta+\cos ^{2} \vartheta\right) \\
& C=\operatorname{sgn}(\vartheta) \sin \vartheta \cos ^{2} \vartheta
\end{aligned}
$$

and:

$$
\delta W=-\operatorname{sgn}(\vartheta) K^{\prime} \sin \delta \vartheta h\left(A+\frac{B h}{2}+\frac{C h^{2}}{3}\right)
$$

By linearizing $\sin \delta \vartheta \cong \delta \vartheta$, it is finally possible to write the restoring moment relative to the spring bed:

$$
M_{r, K^{\prime}}(\vartheta)=-\frac{\partial \delta W(z)}{\partial \vartheta}=\operatorname{sgn}(\vartheta) K^{\prime} h\left(A+\frac{B h}{2}+\frac{C h^{2}}{3}\right)
$$

Considering also the contribution of the self-weight and considering $\vartheta>0$, the global restoring moment $M_{r^{\prime}}(\vartheta)$ is:

$$
M_{r}(\vartheta)=m g R \sin (\alpha-\vartheta)+K^{\prime} h\left(A+\frac{B h}{2}+\frac{C h^{2}}{3}\right)
$$

or, in terms of $R$ :

$$
M_{r}(\vartheta)=m g R \sin (\alpha-\vartheta)+K^{\prime} h\left(A+2 B R \cos \alpha+\frac{4 C R^{2} \cos ^{2} \alpha}{3}\right) .
$$

The spring bed might be active only in a portion of the vertical side, e.g. from depth $z=h^{\prime}>0$ to $z=\bar{h}$. In this more general case, the restoring moment would be:

$$
M_{r}(\vartheta)=m g R \sin (\alpha-\vartheta)+K^{\prime}\left(\bar{h}-h^{\prime}\right)\left[A+\frac{B\left(\bar{h}+h^{\prime}\right)}{2}+\frac{C\left(\bar{h}^{2}+\bar{h} h^{\prime}+h^{\prime 2}\right)}{3}\right] .
$$

For small rotations $\vartheta$, it implies $\sin \vartheta \cong \vartheta$ and $\cos \vartheta \cong 1$; substituting $s=2 R \sin \alpha$ and $h=2 R \cos \alpha$, one obtains $\mathrm{A}=0 ; \mathrm{B}=\mathrm{s} \vartheta^{2} ; \mathrm{C}=\vartheta$; and Equation (34) becomes:

$$
M_{r}(\vartheta)=m g R \sin \alpha\left[1-\vartheta\left(\cot \alpha-\frac{8}{3} \frac{K^{\prime} R^{2}}{m g} \cot \alpha \cos ^{2} \alpha\right)+\vartheta^{2} 4 \frac{K^{\prime} R^{2}}{m g} \cos ^{2} \alpha\right],
$$

By neglecting the second order term depending on $\vartheta^{2}$ one has:

$$
M_{r}(\vartheta)=m g R \sin \alpha\left[1-\vartheta\left(\cot \alpha-\frac{8}{3} \frac{K^{\prime} R^{2}}{m g} \cot \alpha \cos ^{2} \alpha\right)\right],
$$

and the system global stiffness can be written as:

$$
K_{s y s}^{\prime}=m g R \cos \alpha\left(\frac{8}{3} \frac{K^{\prime} R^{2}}{m g} \cos ^{2} \alpha-1\right),
$$

The condition of $K_{s y s}^{\prime}$ to be positive is therefore for rectangular blocks:

$$
K^{\prime}>\frac{3}{2} \gamma \tan \alpha d
$$


where $d$ is the depth of the block in the direction of the axis of rotation. For smeared horizontal restraints the minimum stiffness value does not depend on $R$ but only on the block shape. When blocks are stockier, a higher value of $K^{\prime}$ is required to get the same stabilizing effect. A numerical application can be useful to understand the benefit introduced by the spring bed. Let us assume two blocks with same $R$ but different shape, namely $\alpha=0.32 \mathrm{rad}$ and $\alpha=0.05 \mathrm{rad}$. The results are displayed in Figure 6 .

The minimum values of $K$ to attain positive global stiffness, for the stocky and the more slender block, are respectively $9000 \mathrm{~N} / \mathrm{m}$ and $1350 \mathrm{~N} / \mathrm{m}$ (Equation (40)).

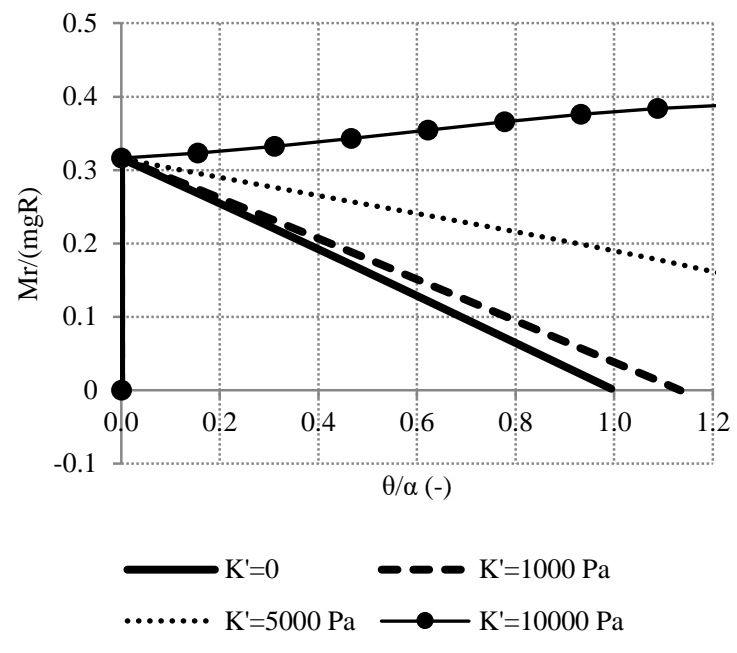

(a)

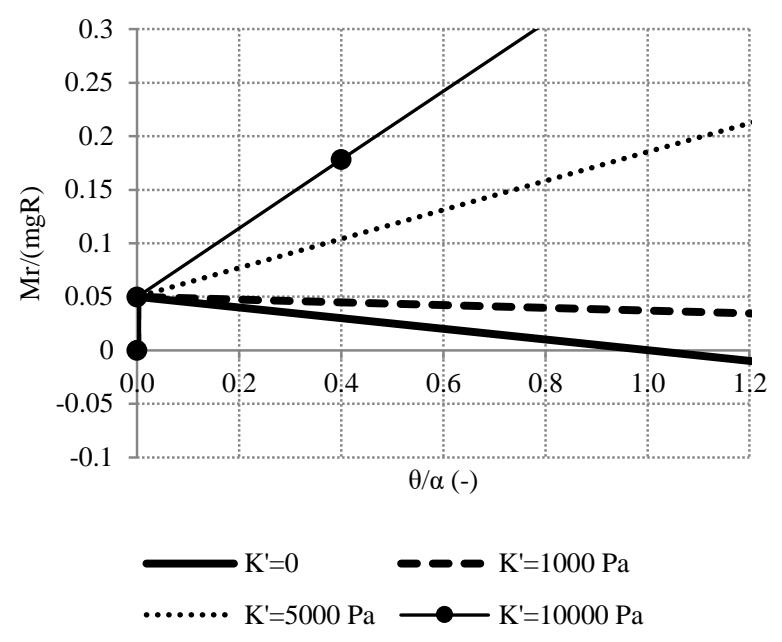

(b)

Figure 6 - Dimensionless moment-rotation amplitude diagram for different values of the spring bed stiffness $\mathrm{K}^{\prime}(R=1.5 \mathrm{~m})$ : (a) $\alpha=0.32 \mathrm{rad}$, (b) $\alpha=0.05 \mathrm{rad}$ (Equation (34)).

The difference between the linearized and the non-linearized expression is less negligible for the stockier block, with an average difference of $-8.9 \%(\mathrm{~K}=0)$ up to $3.4 \%(\mathrm{~K}=10000 \mathrm{~N} / \mathrm{m})$. In other words, in absence of spring bed the restoring moment is overestimated by about $10 \%$ when the linearized expression is considered. For the more slender block, one has a negligible average difference of $+0.05 \%(\mathrm{~K}=0)$ up to $0.15 \%(\mathrm{~K}=10000$ $\mathrm{N} / \mathrm{m}$ ) between the two expressions. Indeed, the linearization has to be adopted carefully for stocky blocks as discussed by Giresini et al. (2015b).

\subsection{Dynamic approach}

The equation of motion of the block restrained by smeared springs can be written from the Housner's equation including in the Euler Lagrange equation the potential energy (Equation (33)):

$$
I_{0} \ddot{\vartheta}+\operatorname{sgn}(\vartheta) m g R \sin (\alpha-\operatorname{sgn}(\vartheta) \vartheta)+\operatorname{sgn}(\vartheta) K^{\prime} \bar{h}\left(A+\frac{B \bar{h}}{2}+\frac{C \bar{h}^{2}}{3}\right)-m g \ddot{u}_{g} R \cos (\alpha-\operatorname{sgn}(\vartheta) \vartheta)=0
$$

where $I_{0}$ is the polar inertia moment with respect to $\mathrm{O}$ and $\ddot{u}_{g}$ is the acceleration time-history (in gravity acceleration $g$ units) and $A, B, C$ are expressed by Equation (31).

Equation (41) can be re-written by distinguishing stabilizing and destabilizing terms:

$$
\ddot{\vartheta}+W_{S T A B}+K_{S T A B}^{\prime}+E_{D E S T}=0
$$

The stabilizing terms are: 


$$
\begin{gathered}
W_{S T A B}=\operatorname{sgn}(\vartheta) \frac{m g R}{I_{0}} \sin (\alpha-\operatorname{sgn}(\vartheta) \vartheta)=\operatorname{sgn}(\vartheta) \frac{3 g}{4} \operatorname{R} \sin (\alpha-\operatorname{sgn}(\vartheta) \vartheta) \\
K_{S T A B}^{\prime}=+\operatorname{sgn}(\vartheta) \frac{K^{\prime} h}{I_{0}}\left(A+\frac{B h}{2}+\frac{C h^{2}}{3}\right)==+\operatorname{sgn}(\vartheta) \frac{K^{\prime}}{I_{0}} f(h)
\end{gathered}
$$

The term with destabilizing effect, representing the earthquake action, is:

$$
E_{D E S T}=-\frac{m g R}{I_{0}} \ddot{u}_{g} \cos (\alpha-\operatorname{sgn}(\vartheta) \vartheta)=-\frac{3}{4} \frac{g}{\mathrm{R}} \ddot{u}_{g} \cos (\alpha-\operatorname{sgn}(\vartheta) \vartheta)
$$

Obviously, only $K_{S T A B}^{\prime}$ differs from the case of single restraint. The terms of the equation for the block previously considered, $\alpha=0.05 \mathrm{rad}$ and $R=1.5 \mathrm{~m}$, are displayed in Figure 7 . The same values of acceleration $\ddot{u}_{g}$ and stiffness as the single restraint case are assumed. Naturally, the difference between $K_{S T A B}^{\prime}$ and $E_{D E S T}$ is much more evident in this case, due to the smeared restraint. The stockier block with $\alpha=0.32 \mathrm{rad}$ and $R=1.5 \mathrm{~m}$ gives similar trends as those shown in Figure 7 without appreciable difference.

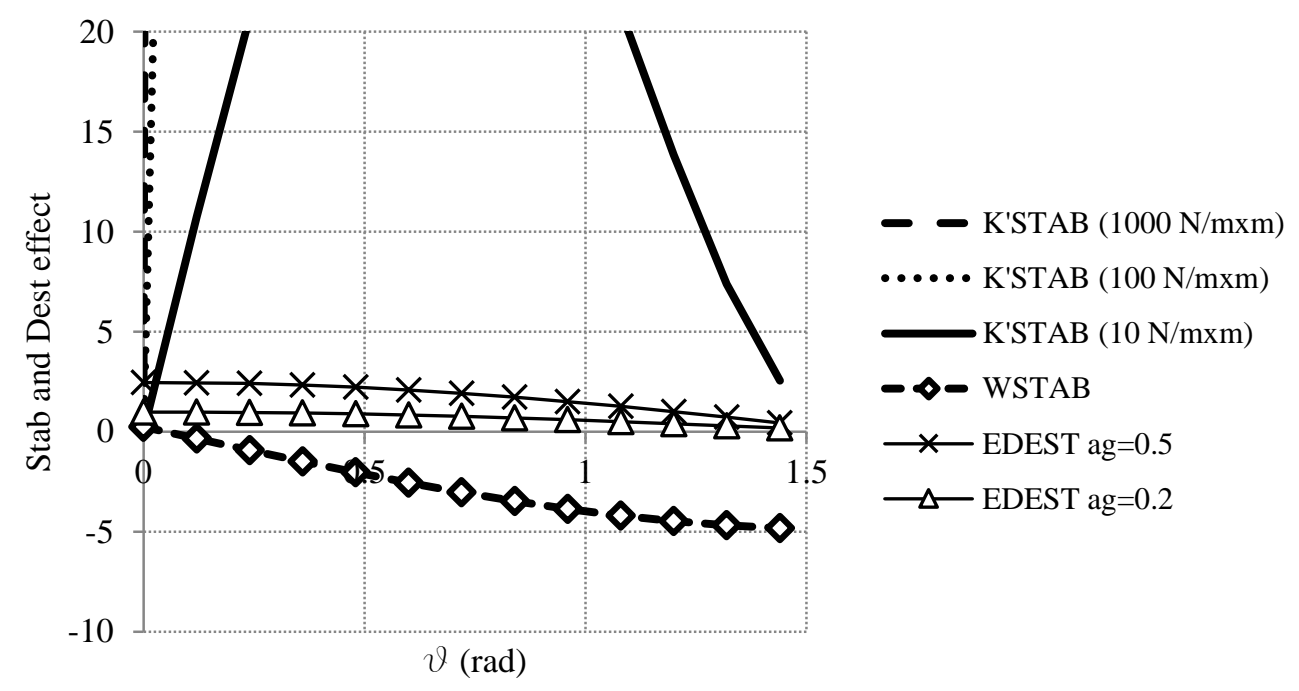

Figure 7 - Stabilizing and destabilizing effect of the terms in the equation of motion $(\alpha=0.05 \mathrm{rad}, R=1.5 \mathrm{~m})$ $\left(K_{S T A B, M A X}^{\prime} \cong 40\right.$ for $\mathrm{K}^{\prime}=10 \mathrm{~N} / \mathrm{m}^{2}, K_{S T A B, M A X}^{\prime} \cong 400$ for $\mathrm{K}^{\prime}=100 \mathrm{~N} / \mathrm{m}^{2}, K_{S T A B, M A X}^{\prime} \cong 4000$ for $\left.\mathrm{K}^{\prime}=1000 \mathrm{~N} / \mathrm{m}^{2}\right)$ smeared horizontal restraint.
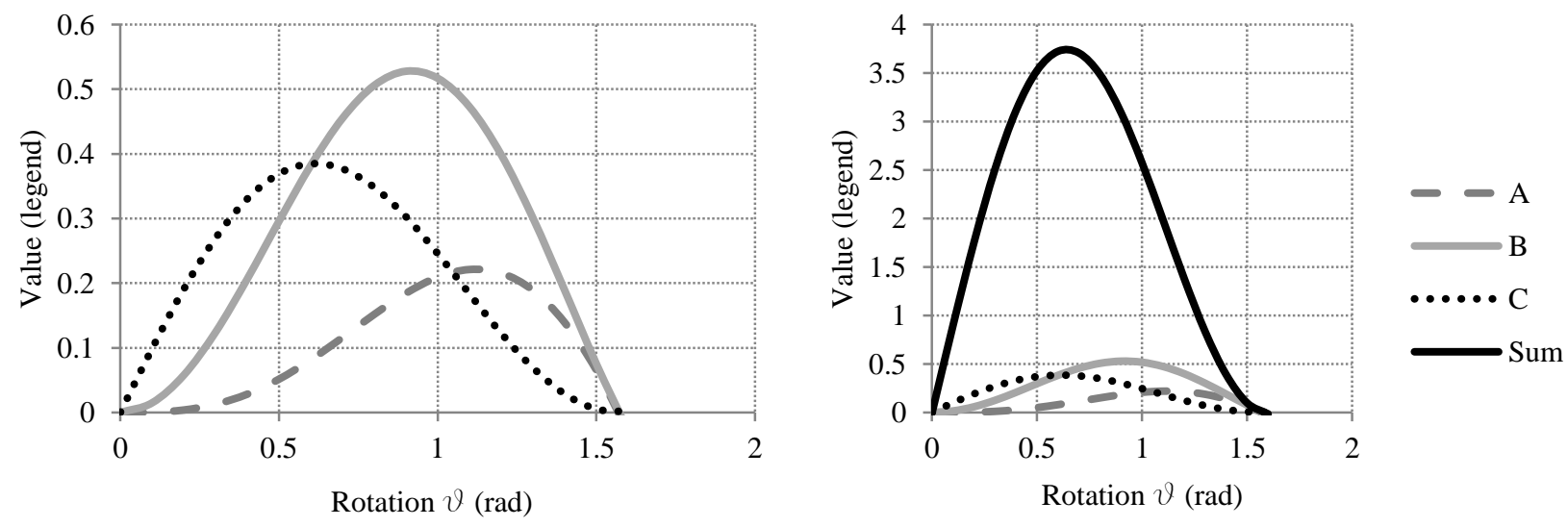

Figure 8 - Stabilizing terms $f(h)$ of Equation (43) - $(\alpha=0.05 \mathrm{rad}, R=1.5 \mathrm{~m})$. 
Referring to a quantitative assessment, one can again state that the ratio between stabilizing and destabilizing effect could be at least three orders of magnitude. This time, the contribution (negative or positive depending on the rotation value) is neglected in favor of simplicity.

$$
\frac{K_{S T A B}^{\prime}}{E_{D E S T}}=\frac{K^{\prime} h\left(A+\frac{B h}{2}+\frac{C h^{2}}{3}\right)}{m g R \ddot{u}_{g} \cos (\alpha-\vartheta)}=\frac{K^{\prime} f(h)}{m g R \ddot{u}_{g} \cos (\alpha-\vartheta)}>1000
$$

The shape of $f(h)$, specialized for the considered numerical case ( $\alpha=0.05 \mathrm{rad}, R=1.5 \mathrm{~m})$, is displayed in Figure 8 . The maximum $f(h)$ value is about 3.7. By substituting the other values in Equation (45), one obtains $K^{\prime}{ }_{\text {min }}=$ $1.1 \mathrm{E} 6 \mathrm{~N} / \mathrm{m}^{2}$. Analogously to what was done for the case of single horizontal restraint, a rocking analysis is performed by integrating Equation (41). The acceleration time-history is again that registered in the El Centro earthquake and the Housner's theoretical value of restitution coefficient was adopted to maximize the response. From Figure 7 and Equation (44), if one assumes as reliable value to impede overturning equal to $\mathrm{K}^{\prime}=100$ $1000 \mathrm{~N} / \mathrm{m}^{2}$, that prevision is not always in favour of safety (Table 2). In the rocking analysis, the stiffness limit of $1.1 \mathrm{E} 6 \mathrm{~N} / \mathrm{m}^{2}$ is enough to make the response safe, as reported in Table 2, obtaining normalized ratio amplitudes lower than 0.5. By contrast, when the value of $\mathrm{K}^{\prime}$ is not sufficient, the spring bed could cause unexpected responses, as collapse for the restrained block that does not fail when it is free (e.g. $K^{\prime}=0$, Ampl.1.0 or 1.1). Moreover, again as in the case of single restraint, the maximum amplitude ratio can overcome that of the case in absence of restraints $\left(\mathrm{K}^{\prime}=1000 \mathrm{~N} / \mathrm{m}^{2}\right)$.

Table 2 - Maximum ratios of normalized rotation amplitude obtained from incremental rocking analysis $(\alpha=0.05 \mathrm{rad}, R=1.5 \mathrm{~m}$, El Centro earthquake, Ampl.= amplification factor $)$ - smeared horizontal restraint

\begin{tabular}{ccccccc} 
Ampl. & $K^{\prime}=0 \mathrm{~N} / \mathrm{mxm}$ & $K^{\prime}=100 \mathrm{~N} / \mathrm{mxm}$ & $K^{\prime}=1000 \mathrm{~N} / \mathrm{mxm}$ & $K^{\prime}=1 E 4 \mathrm{~N} / \mathrm{mxm}$ & $K^{\prime}=1 E 5 \mathrm{~N} / \mathrm{mxm}$ & $K^{\prime}=1 E 6 \mathrm{~N} / \mathrm{mxm}$ \\
\hline 1.0 & 0.712 & overturning & 3.13 & 2.062 & 0.4079 & 0.072 \\
\hline 1.1 & 0.839 & overturning & overturning & 2.264 & 0.4506 & 0.043 \\
\hline 1.2 & overturning & overturning & overturning & 2.652 & 0.4855 & 0.049
\end{tabular}

\subsection{Case of unit stiffness variable with linear law}

In the previous paragraphs the unit stiffness has been considered constant (Figure 9(a)). Nevertheless, in practical cases such as out-of-plane modes of existing masonry buildings, the stiffness cannot be assumed constant but variable with the $\mathrm{z}$ coordinate. In fact, portion of perpendicular walls of triangular shape often participate together with the wall in the rocking response, offering a not uniform transverse stiffness. Let us consider the simplest case of linear variation. Let the spring stiffness at the lowest position be $K_{0}^{\prime}$ and the corresponding spring flexibility or compliance $C^{\prime}{ }_{0}=1 / K_{0}^{\prime}$. If $\Delta C$ is the flexibility increment, the linear variability of the spring flexibility is:

$$
C^{\prime}(\mathrm{z})=\frac{1}{K^{\prime}(z)}=C_{0}^{\prime}+\Delta C \frac{z}{\bar{h}}
$$

where $\bar{h}$ is the maximum height of the spring bed (Figure 9) and $\Delta C$ its variation such as:

$$
\Delta C=\frac{1}{K_{1}^{\prime}}-\frac{1}{K_{0}^{\prime}}=\frac{K_{0}^{\prime}-K_{1}^{\prime}}{K_{0}^{\prime} K_{1}^{\prime}}
$$

By expressing $K^{\prime}(z)$ from Equation (46) taking into account Equation (47) one has: 


$$
K^{\prime}(z)=\frac{K_{0}^{\prime}}{1+\left(\frac{K_{0}^{\prime}}{K_{1}{ }_{1}}-1\right) \frac{Z}{\bar{h}}}=\frac{K_{0}^{\prime}}{1+\Omega z}
$$

being $\Omega=\frac{1}{\bar{h}}\left(\frac{K^{\prime}{ }_{0}}{K^{\prime}{ }_{1}}-1\right)$. The contribution of it to the equation of motion can be now obtained by simply including the variation with $\mathrm{z}$ of the spring stiffness in the integral of Equation (30):

$$
\delta W=-\operatorname{sgn}(\vartheta) K_{0}^{\prime} \sin \delta \vartheta \int_{0}^{\bar{h}} \frac{\mathrm{A}+\mathrm{Bz}+\mathrm{C} \mathrm{z}}{1+\Omega z} \mathrm{dz},
$$

The variation of work done by the spring bed is therefore:

$$
\begin{aligned}
& \delta W=-\operatorname{sgn}(\vartheta) K^{\prime}{ }_{0} \sin \delta \vartheta \mid \frac{A}{\Omega} \ln (1+\Omega z)+\frac{B}{\Omega}\left(z-\frac{1}{\Omega} \ln (1+\Omega z)\right) \\
& +\left.\frac{C}{\Omega^{3}}\left[\frac{(1+\Omega z)^{2}}{2}-2(1+\Omega z)+\ln (1+\Omega z)\right]\right|_{0} ^{\bar{h}},
\end{aligned}
$$

that is:

$$
\begin{aligned}
& \delta W=-\operatorname{sgn}(\vartheta) \frac{K_{0}^{\prime}}{\Omega} \sin \delta \vartheta\left\{A \ln (1+\Omega \bar{h})+B\left(\bar{h}-\frac{1}{\Omega} \ln (1+\Omega \bar{h})\right)\right. \\
& \left.+\frac{C}{\Omega^{2}}\left[\frac{(1+\Omega \bar{h})^{2}}{2}-2(1+\Omega \bar{h})+\ln (1+\Omega \bar{h})+\frac{3}{2}\right]\right\}
\end{aligned}
$$

Obviously, the limit of $\delta W$ as $\Omega$ tends to zero, is given by Equation (32) with $h=\bar{h}$.
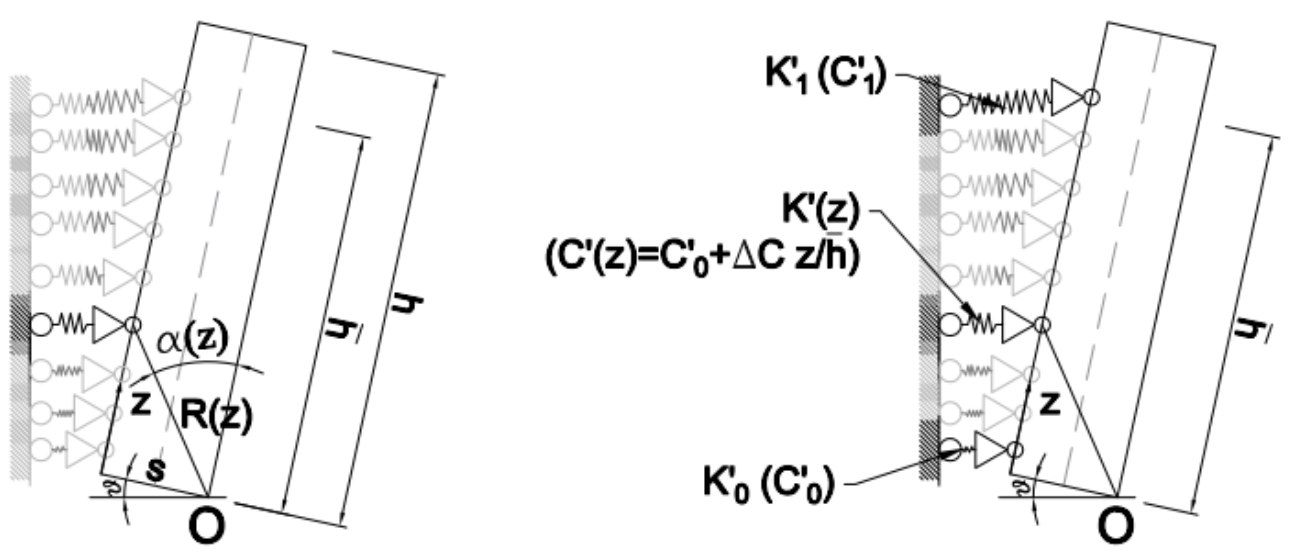

Figure 9. Smeared horizontal restraints varying with linear law of spring flexibility $C^{\prime}(z)$.

Now, the equation of motion can be modified in the general case of linearly variable spring deformability by including the term of the work in the Euler-Lagrange's equation:

$$
\begin{aligned}
I_{0} \ddot{\vartheta}+\operatorname{sgn}(\vartheta) m g R & \sin (\alpha-\operatorname{sgn}(\vartheta) \vartheta) \\
& +\operatorname{sgn}(\vartheta) \frac{K_{0}^{\prime}}{\Omega}\left\{A \ln (1+\Omega \bar{h})+B\left(\bar{h}-\frac{1}{\Omega} \ln (1+\Omega \bar{h})\right)\right. \\
& \left.+\frac{C}{\Omega^{2}}\left[\frac{(1+\Omega \bar{h})^{2}}{2}-2(1+\Omega \bar{h})+\ln (1+\Omega \bar{h})+\frac{3}{2}\right]\right\}-m g \ddot{u}_{g} R \cos (\alpha-\operatorname{sgn}(\vartheta) \vartheta)=0
\end{aligned}
$$

where the terms $A, B, C$ are expressed by Equation (31). 


\section{Parametric analysis and discussion of results}

A parametric analysis was performed by considering different acceleration time-histories, later used for a practical case study in $\S 5$. These earthquakes have been chosen as they have similar PGA and PGV values as those of the El Centro earthquake (Table 3). Indeed, particularly the PGV is a relevant parameter for the risk of collapse in rocking motion. The geometric dimensions and weight are the same adopted in $\S 3$ and $\S 4$, namely $\alpha=0.05 \mathrm{rad}, R=1.5 \mathrm{~m}, \gamma=1.8 \mathrm{E} 4 \mathrm{~N} / \mathrm{m}^{3}$. Both concentrated and smeared restraints are considered. The so obtained rocking spectra, reported in $\S 4.1$ and $\S 4.2$, allow both to identify a safe domain and to confirm the minimum stiffness value obtained from Equations (18)-(20).

Table 3 - Earthquakes used for the parametric analysis of restrained block (PGA=peak ground acceleration, $\mathrm{PGV}=$ peak ground velocity)

\begin{tabular}{|c|c|c|c|c|c|}
\hline \multicolumn{6}{|c|}{ 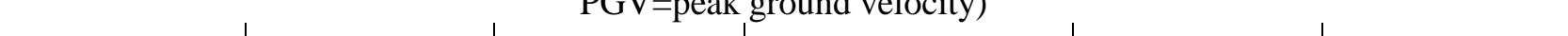 } \\
\hline Station code & $P G A(g)$ & $P G V(\mathrm{~cm} / \mathrm{s})$ & Station code & $P G A(g)$ & $P G V(\mathrm{~cm} / \mathrm{s})$ \\
\hline AQK & 0.334 & 32.210 & $\mathrm{AQG}$ & 0.446 & 30.959 \\
\hline AQA & 0.402 & 31.910 & ELCENTRO & 0.348 & 33.450 \\
\hline
\end{tabular}

\subsection{Parametric dynamic analysis of blocks with single restraint}

By widening the analysis started in $\S 2.2$ (Table 1), one can see that the results are similar adopting different acceleration time-histories. The results are displayed in terms of rocking spectra, intending them as maximum rotation amplitude $(\vartheta / \alpha)_{\max }$ function of the restraint stiffness (Figure 10). The rocking response for different earthquakes with similar characteristics is similar, with and without restraint. Generally, for the same earthquake and the same $\mathrm{K}$ value, a higher position of the restraint $(\beta=2)$ determines a safer conditions, especially for the higher K values. An exception is given by AQK. Moreover, for example for AQG earthquake, overturning does not occur for $\mathrm{K}>1 \mathrm{E} 4 \mathrm{~N} / \mathrm{m}$, but the values of normalized rotations are higher or close to 1 , resulting in a situation not in favour of safety. A good reduction of maximum normalized rotation is achieved for $\mathrm{K} \geq 1 \mathrm{E} 6 \mathrm{~N} / \mathrm{m}$, value suggested by Equation (18). It is relevant to notice that for these values of $\mathrm{K}$, rocking attenuates tending to zero in a monothonic and therefore reliable way. This means that, adopting for value higher than a limit value, higher $\mathrm{K}$, safer the rocking condition.

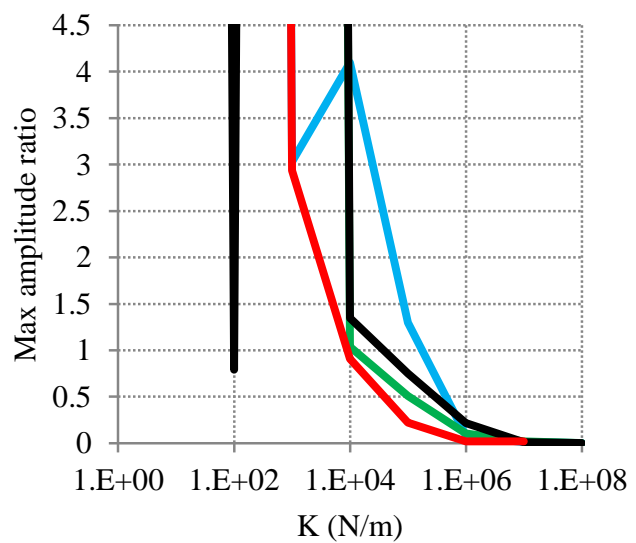

(a)

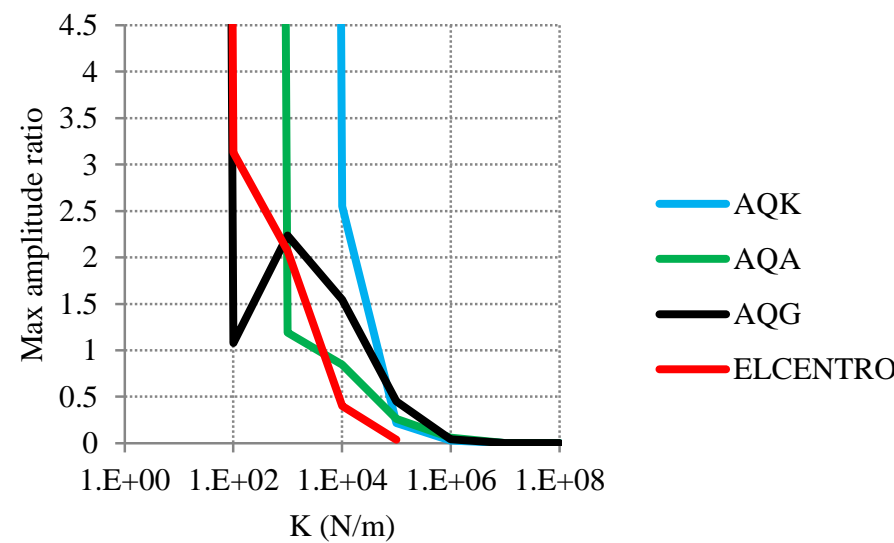

(b)

Figure 10. Parametric analysis of block restrained by a single horizontal spring with $\alpha=0.05 \mathrm{rad}, R=1.5 \mathrm{~m}$, $\gamma=1.8 \mathrm{E} 4 \mathrm{~N} / \mathrm{m}^{3}$ : (a) $\beta=1$; (b) $\beta=2$. 


\subsection{Parametric dynamic analysis of blocks with smeared restraints}

Similarly to what occurred for the single restraint, also for the smeared one higher the stiffness values, lower the maximum amplitude ratio. Different earthquakes with similar characteristics give analogous results, confirming that a minimum stiffness of the order of $1 \mathrm{E} 6 \mathrm{~N} / \mathrm{m}^{2}$ (Equation (45)) is necessary to get a safe response. Also lower values, such as $1 \mathrm{E} 5 \mathrm{~N} / \mathrm{m}^{2}$, can guarantee rocking without overturning, but if one wants to define limit states such as maximum amplitude ratio lower than 0.1 (Dimitrakopoulos and Paraskeva 2015), the value of $1 \mathrm{E} 6 \mathrm{~N} / \mathrm{m}^{2}$ is required.

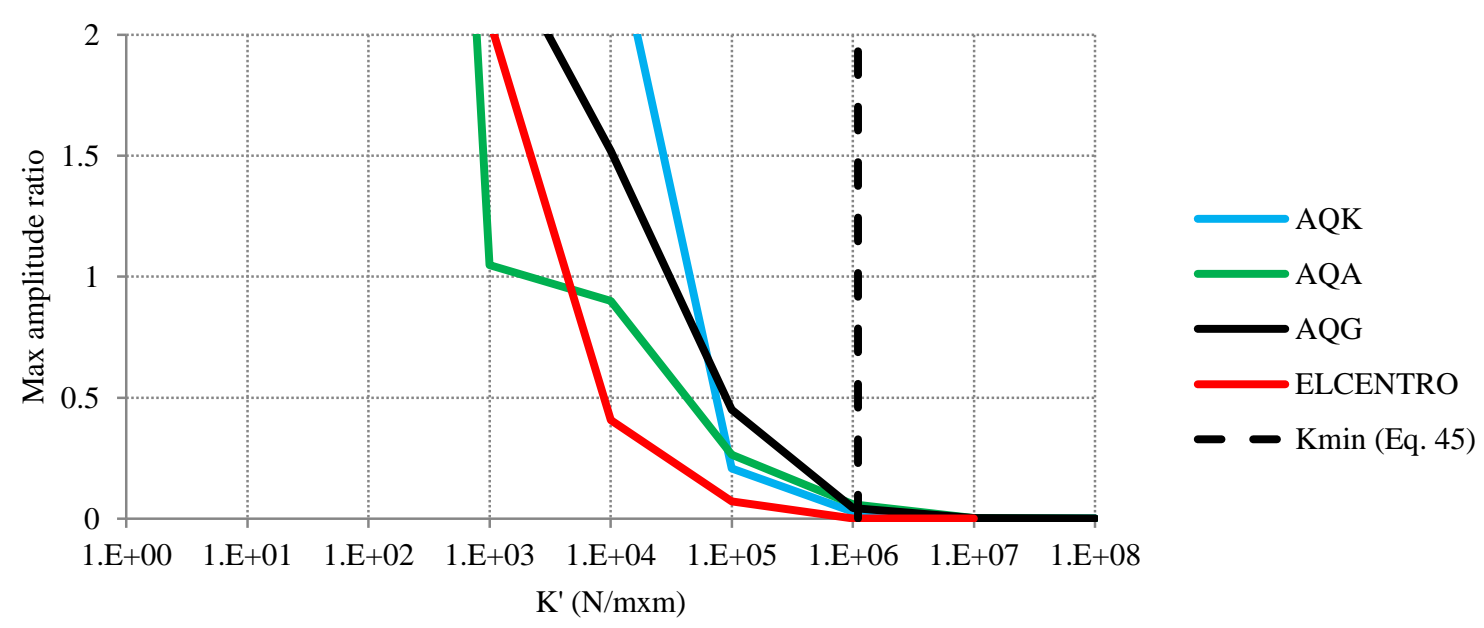

Figure 11. Parametric analysis of block restrained by a smeared bed spring with $\alpha=0.05 \mathrm{rad}, R=1.5 \mathrm{~m}$.

\section{Case study: a masonry church façade}

\subsection{Façade of Santa Gemma church in L'Aquila and seismic records}

The rocking analysis in both linear and non-linear range is applied to the church of S. Gemma Vergine in Goriano Sicoli (L'Aquila, Italy), which was strongly damaged after the 2009 earthquake. The considered boundary conditions are a spring bed with constant stiffness, as discussed in the following. The historic church was built in the 15th century for the first time, and nearly totally rebuilt after a strong earthquake occurred in the 18th century (Di Giannantonio 2003). The three nave church is made of stone masonry and lime stone in the external walls with internal filling and nearly regular texture. The vaults are constructed with brick masonry and lime mortar and the colonnade with inner irregular stone masonry. 


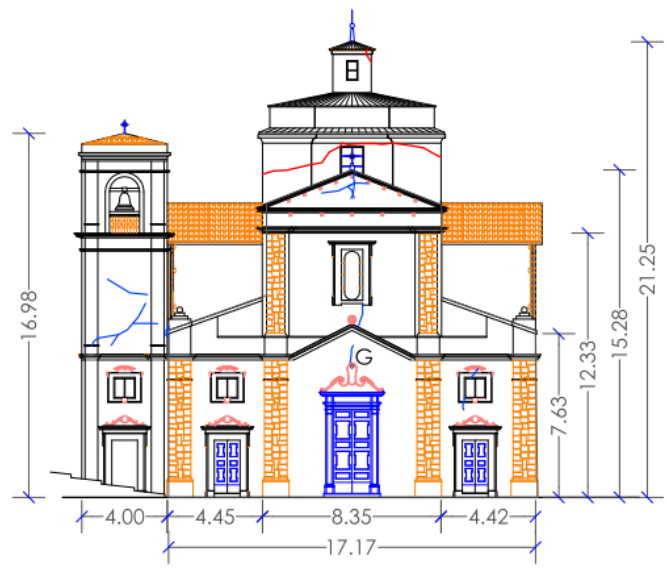

(a)

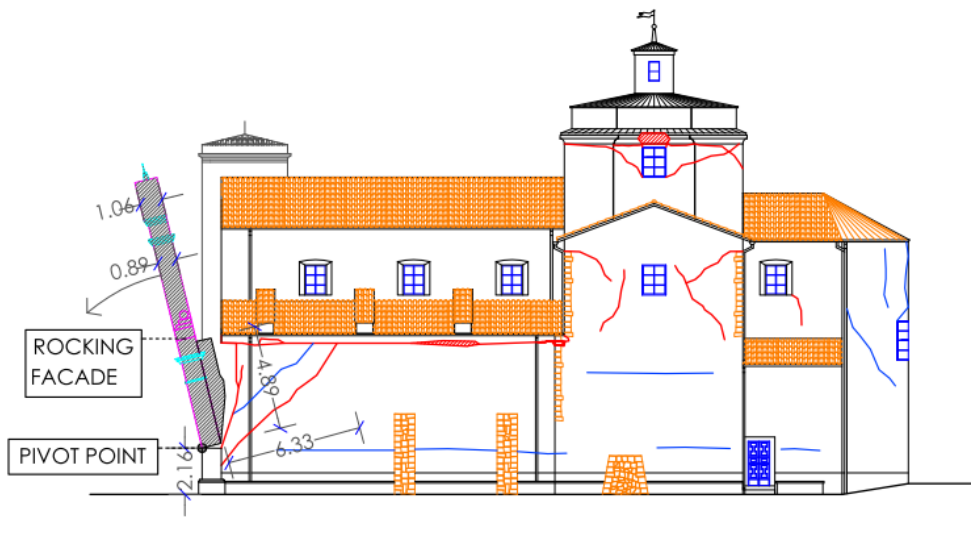

(b)

Figure 12. Santa Gemma church in Goriano Sicoli (AQ): dimensions (in meters, a) and façade rocking mechanism (b).

The church suffered from widespread damage in both structural and non-structural elements from the 2009 earthquake. The non-homogeneous damage on the columns allowed to estimate seismic microzonation effects due to local soil stratigraphy (Sassu et al. 2009). Several collapse mechanisms were identified in the church macro-elements, particularly in the apse and in the main façade (Andreini et al., 2011). The latter was subjected to two out-of-plane modes around horizontal hinge: the first nearly at the base of the wall and the second in correspondence of the tympanum. The first mechanism is here considered and displayed in Figure 12. The final detachment of the façade, with respect to the perpendicular walls, is evident from a visual inspection and the gap between façade and transverse walls is of about $30 \mathrm{~cm}$. In out-of-plane mechanism, a portion of the perpendicular longitudinal walls, $70 \mathrm{~cm}$ long, participated to the rocking motion. The longitudinal walls are here considered as spring bed limited to the lower portion of the façade. By means of a back analysis, the survival of the façade to the seismic records that it experienced can be verified. For calculating the unit stiffness $K^{\prime}$ offered by the longitudinal walls, it is necessary to define masonry elastic modulus, cross section and depth of the walls (in grey in Figure 12). The portion where the stiffness is active (namely $\bar{h}$ in Equation (52)) is 4.9 m long.

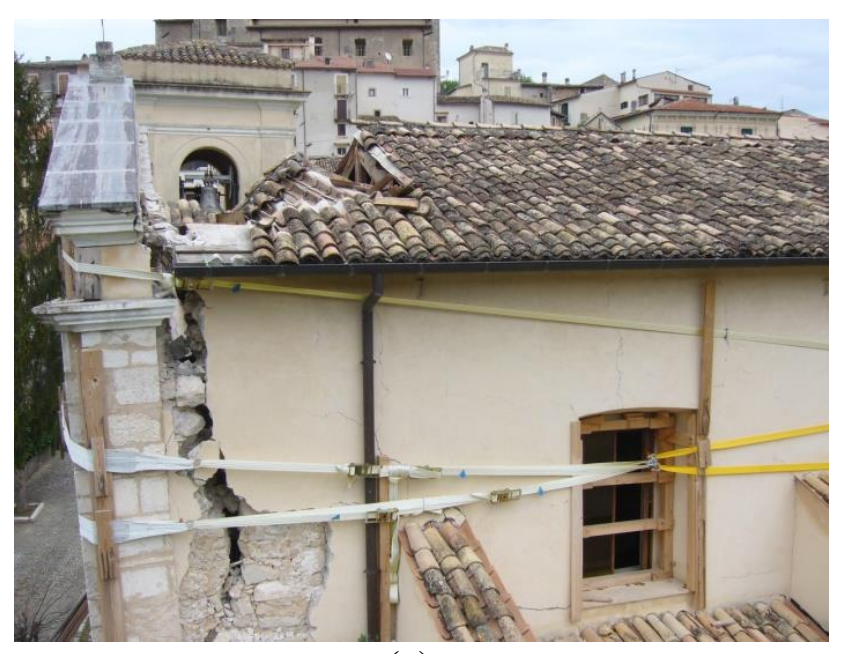

(a)

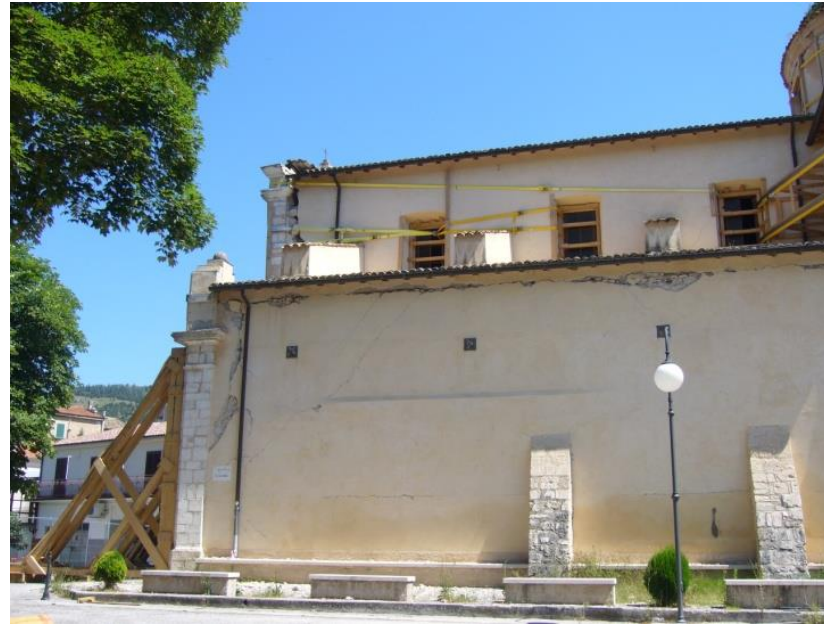

(b)

Figure 13. View from south of the façade mechanism at the top (a) and at the lower part(b). 
Masonry elastic modulus $\mathrm{E}_{\mathrm{y}}$, in vertical direction, was obtained from on site double flat jack tests, taken from similar masonry type specimens tested on site in L'Aquila district, and it is equal to $1700 \mathrm{MPa}$ (Conti 2011). The value of $E_{x}$ adopted in horizontal direction has been taken equal to $E_{y} / 0.8$ according to the masonry type and ratio between block and mortar thickness (Anna Brignola et al. 2008).

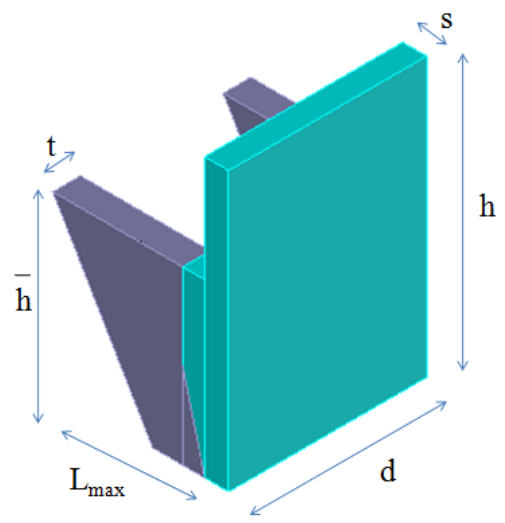

(a)

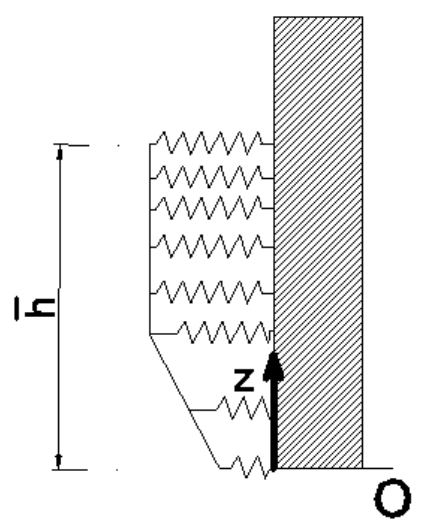

(b)

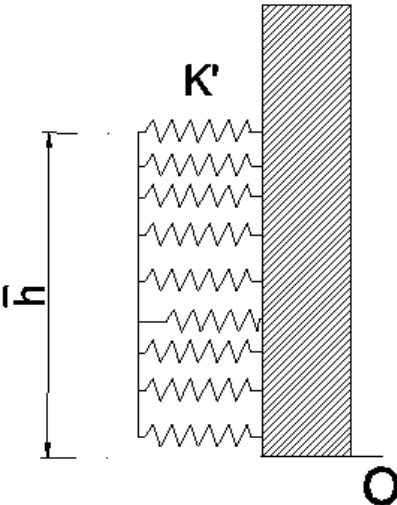

(c)

Figure 14. Horizontal restraints of typical masonry façade connected to transverse walls: (a) rocking façade-cyan and transverse walls as boundary conditions-violet; (b) equivalent rocking block at first step and real smeared constraints; (c) equivalent rocking block and considered smeared constraints in the analysis.

The rocking phenomenon involves the façade in two steps: first the block rocks having as boundary conditions the rectangular perpendicular portion identified by the larger crack, and secondly, when the block is detached as in Figure 12, its center of mass changes by taking into account the increased masonry volume. At this step, boundary conditions are represented by the triangular shape walls visible in Figure 12b as red and blue cracks. The model is described in Figure 14. The two steps can be separately analyzed in the rocking analysis, by considering the first nearly constant stiffness (Equation (41)) and the linearly variable one (Equation (52)). The bed spring stiffness can be defined for masonry walls perpendicular to the façade as:

$$
K^{\prime}=\frac{\mathrm{E}_{\mathrm{x}} \mathrm{A}}{\mathrm{L} \bar{h}}=\mathrm{E}_{\mathrm{x}} \frac{\mathrm{t}}{\mathrm{L}}
$$

being $\mathrm{E}_{\mathrm{x}}$ the elastic modulus in the horizontal direction, $\mathrm{t}$ and $\bar{h}$ respectively the thickness and depth of the participating transverse walls while $\mathrm{A}=\mathrm{t} \bar{h}$ is the perpendicular walls cross section (Figure 11a). L is the length of the perpendicular walls portion involved in the rocking motion, variable with $z$.

By substituting the geometric and mechanical values in Equation (53) assuming the constant stiffness of the first step, one obtains two stiffness values due to the different thicknesses of the perpendicular walls, equal to $0.61 \mathrm{~m}$ and $1.06 \mathrm{~m}$ for left and right side respectively of the façade:

$$
K_{L E F T}^{\prime}=1.85 \mathrm{E} 9 \frac{\mathrm{N}}{\mathrm{m}^{2}} ; K_{R I G H T}^{\prime}=3.22 \mathrm{E} 9 \frac{\mathrm{N}}{\mathrm{m}^{2}} .
$$

By assuming an elastic behavior of the bed spring, these values are simply summed up to get the final value of stiffness equal to $K_{T O T}^{\prime}=5.07 \mathrm{E} 9 \mathrm{~N} / \mathrm{m}^{2}$.

The analysis is carried out by applying the natural seismic records registered nearby the site of Goriano Sicoli during the main shock on 2009 April 6th (ITACA 2.0 earthquake database; Luzi et al. 2008). All the seismic records considered are referred to West-East orientation due to the façade position (Table 4). 
Table 4. Seismic records features, 2009-04-06 UTC01:32:40, $\mathrm{M}_{\mathrm{W}}=6.3, \mathrm{M}_{\mathrm{L}}=5.9$, orientation West-East $\left(R_{\text {epi }}\right.$ : distance of the station from the epicentre; distance: distance of the church from the station; $P G A, P G V$, $P G D$ : peak ground acceleration, velocity, displacement).

\begin{tabular}{ccccccc} 
Station code & Eurocode 8 soil type & Repi $(\mathrm{km})$ & Distance $(\mathrm{km})$ & PGA $\left(\mathrm{cm} / \mathrm{s}^{2}\right)$ & PGV $(\mathrm{cm} / \mathrm{s})$ & PGD $(\mathrm{cm})$ \\
\hline AQV & B & 5.1 & 58 & 644.247 & -40.206 & 6.787 \\
\hline AQK & B & 1.8 & 53 & 327.730 & -32.210 & 7.191 \\
\hline AQA & B & 5.2 & 60 & 394.745 & 31.910 & 5.429 \\
\hline AQG & B & 5.1 & 60 & -437.428 & -30.959 & 5.995 \\
\hline CLN & B* & 30.6 & 25 & -79.780 & 4.857 & -2.877 \\
\hline SUL & A* & 53.6 & 20 & -33.680 & -2.800 & 1.006
\end{tabular}

\subsection{Rocking analysis}

The analysis is performed in non-linear assumptions (Figure 2), since for clockwise rotation the perpendicular masonry walls are compressed and behave as horizontal restraint, while in the counterclockwise rotation, when rocking motion is activated and masonry is no tension resistant, any restraint is available. However, the rocking analysis is also carried out considering the linear case, where in both rotations the stiffness is supposed to act. Other approaches on the evaluation of one-sided rocking motion are available in the literature, as those that reduce the velocity after impact by a damping coefficient together with the restitution coefficient (Sorrentino et al., 2008). A parametric analysis allows to make some considerations about the response of the restrained block. The adopted parameter is the stiffness spring bed, assumed to vary between 0 (free-standing block) and $1 \mathrm{E} 12 \mathrm{~N} / \mathrm{m}^{2}$ with intervals of one order of magnitude $\left(0,10,100,1 \mathrm{E} 3, \ldots, 1 \mathrm{E} 12 \mathrm{~N} / \mathrm{m}^{2}\right)$. The overturning condition is fixed to $\left(\frac{\vartheta}{\alpha}\right)_{\max }>10$.

The outcomes of the parametric analysis applied to the main façade of Santa Gemma church are reported in Figure 15. Such graphs are a sort of failure domains of the rocking block subjected to several seismic actions and variable boundary conditions (Giresini et al. 2015a). When the façade is stable, the maximum amplitude ratio $(\vartheta / \alpha)_{\max }$ is below 1.0 (Figure 15(a),(b)). A higher number of overturning results for the seismic records with higher PGV (AQV and AQK with $40 \mathrm{~cm} / \mathrm{s}$ and $32 \mathrm{~cm} / \mathrm{s}$ respectively).

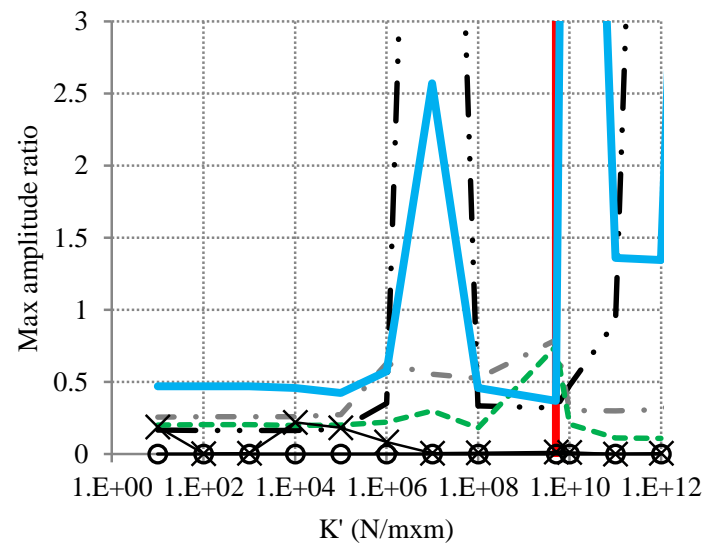

(a)

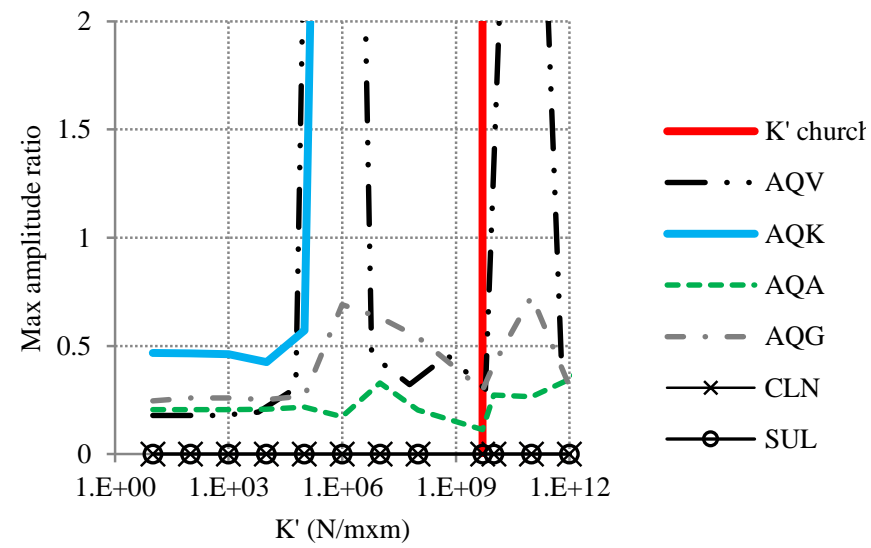

(b) 


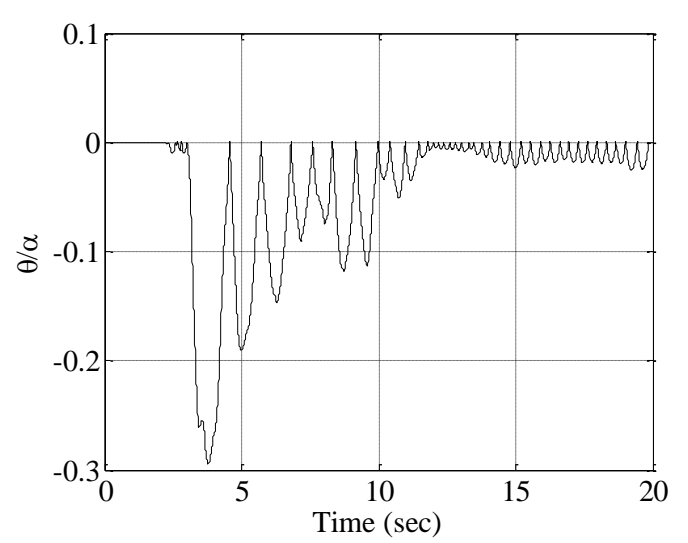

(c)

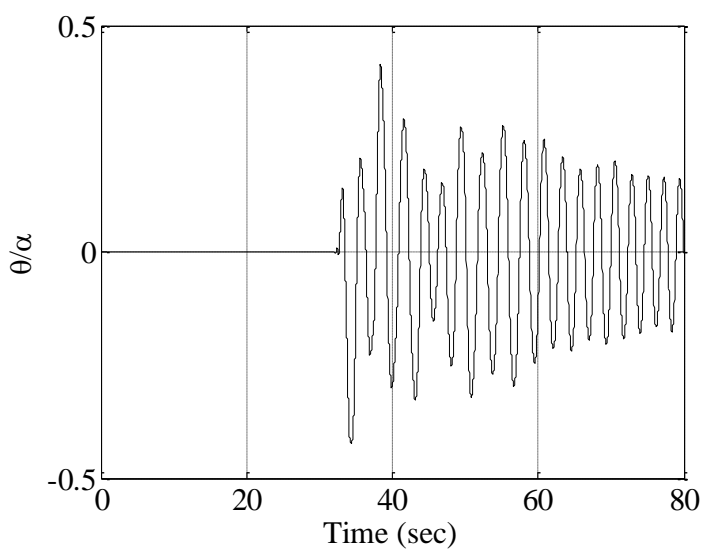

(e)

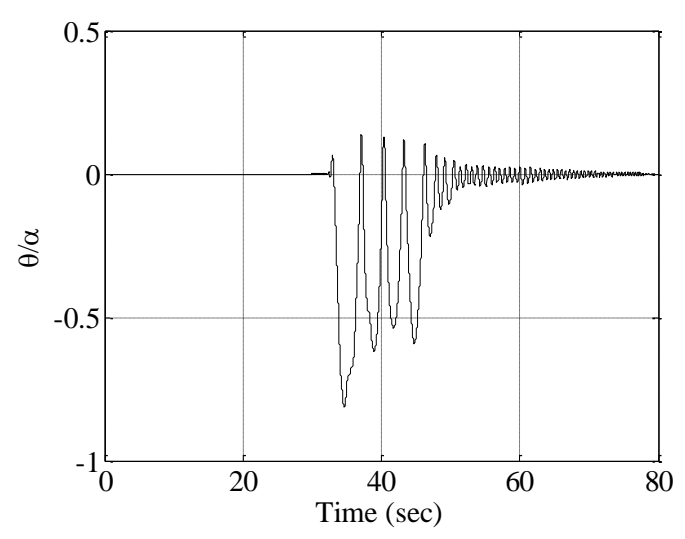

(d)

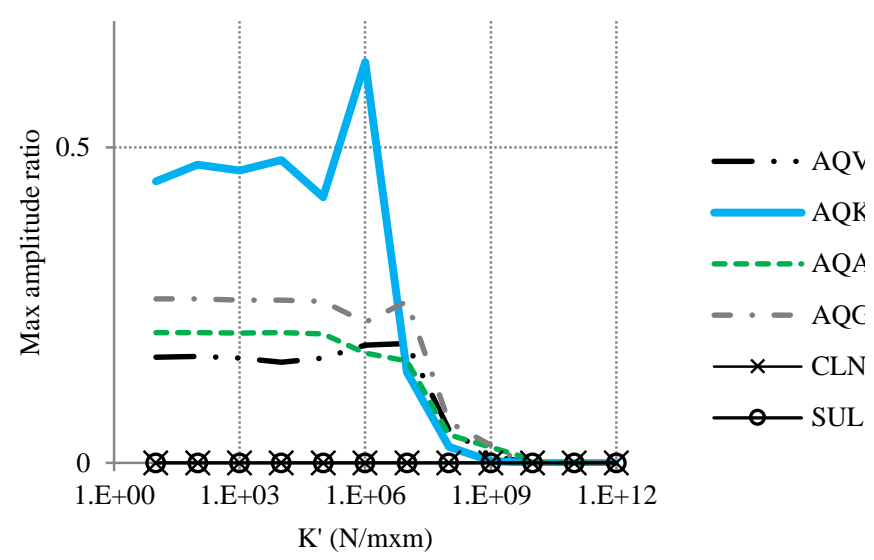

(f)

Figure 15. Rocking analysis results of the façade of Santa Gemma church in Goriano Sicoli: (a) non-linear case in the real configuration; (b) non-linear case with bed spring smeared over the whole height of the façade; (c) façade subjected to AQV record and $K_{T O T}^{\prime}=5.07 \mathrm{E} 9 \mathrm{~N} / \mathrm{m}^{2}$; (d) façade subjected to AQK seismic record and $K_{T O T}^{\prime}=1 \mathrm{E} 7 \mathrm{~N} / \mathrm{m}^{2}$; (e) oscillatory motion for non-linear case and value of stiffness $\mathrm{K}^{\prime}=1 \mathrm{E} 6 \mathrm{~N} / \mathrm{m}^{2}$ and $\mathrm{AQK}$ record; (f) linear case in the real configuration.

However, a slightly lower PGV value of $31 \mathrm{~cm} / \mathrm{s}$ (that of AQA seismic record) does not imply any collapse. The response is strongly influenced by the stiffness value for the earthquakes with higher intensity. There is not a correspondence between the entity of non-linear stiffness and probability of collapse. However, the church façade is stable as displayed in Figure 15(a). If the restraint was smeared over the whole height of the façade, the safe domain would have been slightly reduced (Figure 15 (b)).

The rebound effect exerted by the perpendicular walls is clear in Figure 15(c). Indeed, for K' higher than 1E6 $\mathrm{N} / \mathrm{m}^{2}$ (for AQK action, (d)) the rebound effect is visible while with lower stiffness values the motion is oscillatory Figure 15(c), since the bed spring does not affect the response enough. Finally, the linear case shows that higher the stiffness, lower the maximum amplitude ratio. The minimum value of $K^{\prime}$ to obtain a positive global stiffness is given by Equation (40) and is equal to $2.1 \mathrm{E} 4 \mathrm{~N} / \mathrm{mxm}$.

This is valid for all the seismic records and it is a reason why it is preferable to have similar stiffness in clockwise and counterclockwise rotations to achieve a reduction of amplitude ratio by increasing it. It is worthy to notice that some values of stiffness can worsen the block response with respect to the free-standing condition in both non-linear (Figure 15(a),(b)) and linear (Figure 15(f)) cases. 


\section{Common values of unit stiffness for masonry and r.c. panels}

Theoretically the lower limit of unit stiffness of the spring bed is not of interest in performing parametric analysis, since the block might be free-standing. By contrast, to define an upper limit of unit stiffness could be relevant for structural engineers who want to verify the seismic vulnerability assessment of a rigid block however restrained. The bed spring stiffness can be defined for masonry walls/r.c. panels perpendicular to the rigid block and connected to it as expressed in Equation (53). The masonry elastic modulus $\mathrm{E}_{\mathrm{y}}$, in vertical direction, can be obtained from on site tests such as double flat jack tests.

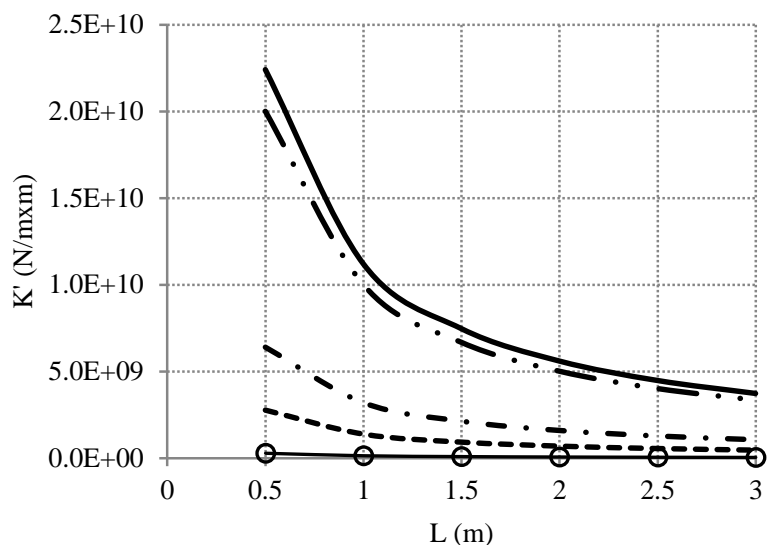

- $\mathrm{t}=0.1 \mathrm{~m}, \mathrm{E}=690 \mathrm{MPa}-\boldsymbol{-}-\cdot \mathrm{t}=1 \mathrm{~m}, \mathrm{E}=690 \mathrm{MPa}$

$\longrightarrow \mathrm{t}=1 \mathrm{~m}, \mathrm{E}=5600 \mathrm{MPa}-\cdots \mathrm{t}=1 \mathrm{~m}, \mathrm{E}=1600 \mathrm{MPa}$

- $\cdot \mathrm{t}=0.20 \mathrm{~m}$, concrete

(a)

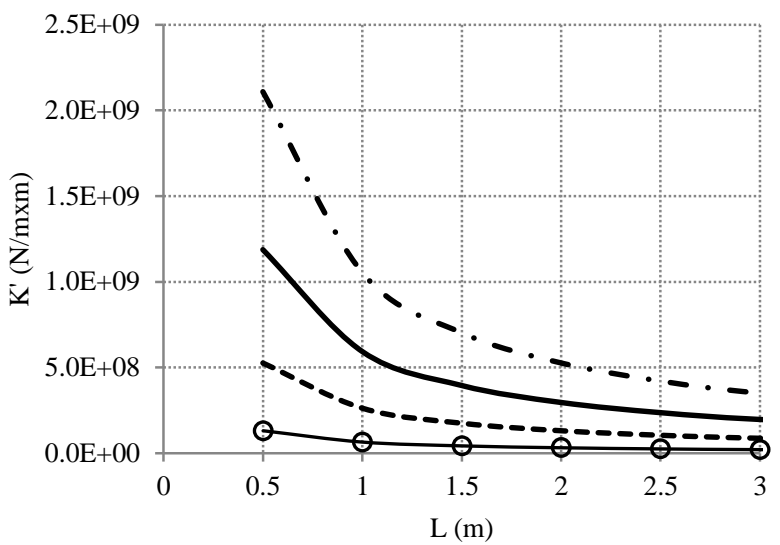

$\longrightarrow \mathrm{d}=1 \mathrm{~cm}, 2 \times 2$ tie-rods $/ \mathrm{m}-\cdots \mathrm{d}=2 \mathrm{~cm}, 2 \times 2$ tie-rods $/ \mathrm{m}$

$\longrightarrow \mathrm{d}=3 \mathrm{~cm}, 2 \times 2$ tie-rods $/ \mathrm{m}-\cdots \mathrm{d}=4 \mathrm{~cm}, 2 \times 2$ tie-rods $/ \mathrm{m}$

(b)

Figure 16. Orders of magnitude of bed spring stiffness: (a) two masonry/concrete walls, stiffness depending on elastic modulus, thickness and depth of perpendicular walls; (b) four steel tie-rods/m with different diameter

This mechanical parameter can be used for defining the horizontal modulus $\mathrm{E}_{\mathrm{x}}$ with coefficients depending on the masonry type (stone or brick), on the ratio of block modulus over mortar modulus and on the ratio mortar to block thickness (Anna Brignola et al. 2008). In absence of experimental tests, range of values of elastic modulus are given by the Italian codes (Circ. espl. 02.02.2009) for existing masonry. The minimum elastic modulus is equal to $690 \mathrm{MPa}$ for irregular stone masonry, whereas the maximum is $5600 \mathrm{MPa}$ for solid brick and cement mortar. For historic buildings made of brick and lime mortar, a common average value provided by the codes is $1600 \mathrm{MPa}$. Maximum and minimum thickness of perpendicular masonry walls can be 1.0 and $0.1 \mathrm{~m}$, while a reference value of $0.20 \mathrm{~m}$ could be assumed for concrete. By varying the depth of the perpendicular walls, it is possible to assess that the range of values of stiffness is between $2 \mathrm{E} 8 \mathrm{~N} / \mathrm{m}^{2}$ and $2 \mathrm{E} 10$ $\mathrm{N} / \mathrm{m}^{2}$ (Figure 16(a)). Naturally, for depth lower than $50 \mathrm{~cm}$ much higher stiffness value can be obtained, but those are not significant from an engineering point of view.

In Figure 16(b) the stiffness of two steel tie-rods/m per each perpendicular wall is obtained for different parameters and tie-rod length. As maximum values of the order of $1 \mathrm{E} 9$ and $1 \mathrm{E} 8 \mathrm{~N} / \mathrm{m}^{2}$ are obtained for diameter of respectively $4 \mathrm{~cm}$ and $1 \mathrm{~cm}$. These abaci can provide preliminary values for the stiffness of steel tie-rods to be used for historical constructions (De Falco et al. 2013, These values are then comparable to those calculated for masonry walls and can be taken into account for obtaining an oscillatory motion. Indeed, when the stiffness is different depending on the sign rotation (see section 5) a rebound effect can emerge and could cause overturning. If a masonry façade rocking against perpendicular walls is unstable under a given set of acceleration time-histories due to a rebound effect, the panel can be restrained by steel tie-rods commonly used 
in retrofitting techniques of historic structures. The benefit introduced by them can therefore be assessed with a rocking analysis. If the stiffness is the same order of magnitude in clockwise and counterclockwise rotations it generally implies oscillatory motion, without potentially risky rebound effect.

\section{Conclusions}

This paper deals with the dynamics of horizontally restrained blocks. For two type of restraints, one concentrated with variable position and another smeared as spring bed, the equations of motion were obtained. The check of stabilizing and destabilizing terms can provide a first information on the effectiveness of the strengthening system, defined by a stiffness value. Minimum stiffness values can be set before performing rocking analysis to get a safe response. The obtained expressions of minimum stiffness have been confirmed by full dynamic analyses. Moreover, it was shown that sometimes low stiffness values could cause block overturning, even though the free-standing block is stable under a given earthquake.

When the same stiffness value is considered in clockwise and counterclockwise rotation, the rocking motion is oscillatory and tends to vanish for high stiffness values. It must be noticed that strengthening measures generally act only in one-sided motion for civil engineering applications. In this case, unstable effects due to the rebound effect can emerge when a finite value of stiffness is assumed for clockwise rotation and very low or null value is considered for counterclockwise rotation and vice-versa. In a non-linear range with different values of stiffness in clockwise and counterclockwise rotations, there exists a minimum stiffness value, under which the motion is oscillatory since the restraint does not influence enough the response. This minimum value depends on the considered seismic record. In case of very different values of stiffness in clockwise and counterclockwise rotations, overturning occurs due to the rebound effect without any failure correspondence with the stiffness value. It is then preferable to have similar stiffness in clockwise and counterclockwise rotations to achieve a reduction of amplitude ratio by increasing this stiffness and make the response safer.

\section{References}

Acikgoz, S.; DeJong, M.J. (2014) The rocking response of large flexible structures to earthquakes. In Bulletin of Earthquake Engineering 12 (2), pp. 875-908. DOI: 10.1007/s10518-013-9538-0.

Andreini, M.; Conti, T.; Masiello, G.; Sassu, M.; Vezzosi, A.: La Chiesa Di Santa Gemma A Goriano Sicoli (AQ): Input Sismico E Meccanismi Di Danno (2011) Workshop on design for rehabilitation of masonry structures, Florence, November 2011., vol. 4, pp. 1-12.

Andreini, M.; De Falco, A.; Giresini, L.; Sassu, M. (2013) Structural analysis and consolidation strategy of the historic Mediceo Aqueduct in Pisa (Italy). Applied Mechanics and Materials, vol. 351-352, 1354-1357, Trans Tech Publication, ISBN: 9783037857748, ISSN: 1662-7482, DOI: 10.4028/www.scientific.net/AMM.351352.1354

Andreini, M.; De Falco, A.; Giresini, L.; Sassu, M. (2014) Structural damage in the cities of Reggiolo and Carpi after the earthquake on May 2012 in Emilia Romagna. In Bulletin of Earthquake Engineering 12 (5), pp. 2445-2480, DOI: $10.1007 / \mathrm{s} 10518-014-9660-7$

Brignola A.; Frumento S.; Lagomarsino S.; Podestà S. (2008) Identification of Shear Parameters of Masonry Panels Through the In-Situ Diagonal Compression Test. In International Journal of Architectural Heritage 3 (1), pp. 52-73. DOI: 10.1080/15583050802138634.

NTC2008 (1/14/2008): Approvazione delle Nuove Norme Tecniche per le Costruzioni. In : Gazzetta Ufficiale della Repubblica Italiana n. 29, February, 28th 2008, Supplemento Ordinario n. 30. 
Beck, J. L.; Skinner, R. I. (1973) The seismic response of a reinforced concrete bridge pier designed to step. In Earthquake Engineering \& Structural Dynamics 2 (4), pp. 343-358. DOI: 10.1002/eqe.4290020405.

Casapulla, C.; Jossa, P.; Maione, A. (2010) Rocking motion of a masonry rigid block under seismic actions: A new strategy based on the progressive correction of the resonance response. In Ingegneria Sismica 27 (4), pp. 35-48.

Casapulla, C.; Cascini, L.; Portioli, F.; Landolfo, R. (2014) 3D macro and micro-block models for limit analysis of out-of-plane loaded masonry walls with non-associative Coulomb friction. In Meccanica 49 (7), pp. 1653-1678.

Casapulla, C. (2015) On the resonance conditions of rigid rocking blocks. In International Journal of Engineering and Technology 7 (2), pp. 760-761.

Casapulla, C.; Portioli, F. (2016) Experimental tests on the limit states of dry-jointed tuff blocks. Materials and Structures 49 (3), pp. 751-767.

Circolare M.I.T. n.617 del 02.02.2009 "Istruzioni per l'applicazione delle nuove norme tecniche per le costruzioni di cui al D.M. 14.01.2008” (In italian).

Conti, T. (2011) Rischio Sismico E Consolidamento Di Volte In Laterizio Nella Chiesa Di Santa Gemma A Goriano Sicoli (AQ). Master Thesis. University of Pisa, Pisa.

De Falco, A.; Giresini, L.: Sassu, M. (2013). Temporary preventive seismic reinforcements on historic churches: numerical modeling of San Frediano in Pisa. Applied Mechanics and Materials, vol. 352, 13931396, Trans Tech Publication, ISBN: 9783037857748, ISSN: 1393-1396, DOI: 10.4028/www.scientific.net/AMM.351-352.1393

DeJong, M. J. (2012) Amplification of Rocking Due to Horizontal Ground Motion. In Earthquake Spectra 28 (4), pp. 1405-1421. DOI: 10.1193/1.4000085.

DeJong, M. J.; Dimitrakopoulos, E. G. (2014) Dynamically equivalent rocking structures. In Earthquake Engng Struct. Dyn. 43 (10), pp. 1543-1563. DOI: 10.1002/eqe.2410.

Di Giannantonio, R. (2003) Goriano Sicoli - storia ed arte nel paese di Santa Gemma - l'arte e l'architettura. Corfinio (L'Aquila): Amaltea.

Dimitrakopoulos E.G.; Paraskeva, T.S. (2015) Dimensionless fragility curves for rocking response to nearfault excitations, Earthquake Engng Struct. Dyn. 44 (12), pp. 2015-2033. DOI: 10.1002/eqe.2571.

Giresini, L. (2015) Energy-based method for identifying vulnerable macro-elements in historic masonry churches, Bulletin of Earthquake Engineering, 44(13) 2359-2376. DOI: 10.1002/eqe.2592.

Giresini, L.; Fragiacomo, M.; Lourenço, P. B. (2015a) Comparison between rocking analysis and kinematic analysis for the dynamic out-of-plane behavior of masonry walls. In Earthquake Engineering and Structural Dynamics. DOI: 10.1002/eqe.2592.

Giresini, L.; Fragiacomo, M.; Sassu, M. (2015b) Rocking analysis of masonry walls interacting with roofs. In Engineering Structures, 116, 107-120. DOI: 10.1016/j.engstruct.2016.02.041.

Giresini, L. (2015c) Modelling techniques and rocking analysis for historic structures: influence of vaulted systems in the seismic response of churches. In Ph.D. Thesis, University of Pisa.

Housner, G. W. (1963) The behavior of inverted pendulum structures during earthquakes. In Bulletin of the Seismological Society of America 53 (2), pp. 403-417.

ITACA 2.0 earthquake database. http://itaca.mi.ingv.it; Luzi et al., 2008; Pacor et al., 2011. 
Lagomarsino, S. (2012) Damage assessment of churches after L'Aquila earthquake (2009). In Bulletin of Earthquake Engineering 10 (1), pp. 73-92. DOI: 10.1007/s10518-011-9307-x.

Lipscombe, P. R.; Pellegrino, S. (1993) Free rocking of prismatic blocks. In Journal of Structural Engineering 119 (7), pp. 1387-1410. DOI: 10.1061/(ASCE)0733-9399(1993)119:7(1387).

Luzi, L.; Hailemikael, D.; Bindi D.; Pacor, F.; Mele, F.; Sabetta F. (2008) A Web Portal for the Dissemination of Italian Strong-motion Data, Seismological Research Letters. In Seismological Research Letters 75 (9), pp. 716-722. DOI: 10.1785/gssrl.79.5.716.

Makris, N. (2014) The Role of the Rotational Inertia on the Seismic Resistance of Free-Standing Rocking Columns and Articulated Frames. In Bulletin of the Seismological Society of America 104 (5), pp. 2226-2239. DOI: $10.1785 / 0120130064$.

Makris, N.; Roussos, Y. S. (2000) Rocking response of rigid blocks under near-source ground motions. Géotechnique. In Géotechnique 50 (3), pp. 243-262. DOI: 10.1680/geot.2000.50.3.243.

Makris, N.; Vassiliou, M. F. (2014) Dynamics of the Rocking Frame with Vertical Restrainers. In J. Struct. Eng., p. 4014245. DOI: 10.1061/(ASCE)ST.1943-541X.0001231.

Rovero, L.; Alecci, V.; Mechelli, J.; Tonietti, U.; Stefano, M. de (2015) Masonry walls with irregular texture of L'Aquila (Italy) seismic area: validation of a method for the evaluation of masonry quality. In Materials and Structures, pp. 1-18. DOI: 10.1617/s11527-015-0650-2.

Sassu, M.; Conti, T.; Masiello, G.; Vezzosi, A. (2009) La Chiesa di Santa Gemma a Goriano Sicoli. In L'UNIVERSITÀ E LA RICERCA PER L'ABRUZZO - Il come e il perché dei danni a 48 monumenti L'Aquila 17-19 dicembre 2009.

Sharpe, R. D.; Skinner, R. I. (1983) The seismic design of an industrial chimney with rocking base. In Bull N Z Natl Soc Earthq Eng 16 (2), pp. 98-106.

Sorrentino, L.; Kunnath, S.; Monti, G.; Scalora, G. (2008): Seismically induced one-sided rocking response of unreinforced masonry façades, Engineering Structures, 30(8), 2140-215, DOI: 10.1016/j.engstruct. 2007.02.021.

Sorrentino, L.; Masiani, R.; Decanini, L. D. (2006): Overturning of rocking rigid bodies under transient ground motions. In Structural Engineering and Mechanics 22 (3), pp. 293-310. DOI: 10.12989/sem.2006. 22.3.293. 